\title{
Genitourinary AND ObSTETRIC RADIOLOGY
}

\section{Tuberculosis of the genitourinary system-Urinary tract tuberculosis: Renal tuberculosis-Part I}

\author{
Suleman Merchant, Alpa Bharati, Neesha Merchant ${ }^{1}$ \\ Department of Radiology, LTM Medical College and LTM General Hospital, Mumbai, India, 'Department of Radiology, \\ University Health Network, University of Toronto, Toronto, Canada
}

Correspondence: Prof. Suleman Merchant, Head - Department of Radiology and Dean, LTM Medical College and LTM General Hospital, Mumbai, India. E-mail: suleman_merchant@hotmail.com

\begin{abstract}
Tuberculosis (TB) remains a worldwide scourge and its incidence appears to be increasing due to various factors, such as the spread of human immunodeficiency virus (HIV) and acquired immunodeficiency syndrome (AIDS). The insidious onset and non-specific constitutional symptoms of genitourinary tuberculosis (GUTB) often lead to delayed diagnosis and rapid progression to a non-functioning kidney. Due to hematogenous dissemination of TB, there is a potential risk of involvement of the contralateral kidney too. Imaging plays an important role in the making of a timely diagnosis and in the planning of treatment, and thus helps to avoid complications such as renal failure. Imaging of GUTB still remains a challenge, mainly on account of the dearth of literature, especially related to the use of the newer modalities such as magnetic resonance imaging (MRI). This two-part article is a comprehensive review of the epidemiology, pathophysiology, and imaging findings in renal TB. Various imaging features of GUTB are outlined, from the pathognomonic lobar calcification on plain film, to finer early changes such as loss of calyceal sharpness and papillary necrosis on intravenous urography (IVU); to uneven caliectasis and urothelial thickening, in the absence of renal pelvic dilatation, as well as the hitherto unreported 'lobar caseation' on ultrasonography (USG). Well-known complications of GUTB such as sinus tracts, fistulae and amyloidosis are described, along with the relatively less well-known complications such as tuberculous interstitial nephritis (TIN), which may remain hidden because of its 'culture negative' nature and thus lead to renal failure. The second part of the article reviews the computed tomography (CT) and MRI features of GUTB and touches upon future imaging techniques along with imaging of TB in transplant recipients and in immunocompromised patients.
\end{abstract}

Key words: Renal tuberculosis; tuberculous interstitial nephritis; intravenous urography; ultrasonography; lobar caseation; uneven caliectasis

\section{Introduction}

Tuberculosis (TB), is the commonest worldwide cause of mortality from infectious disease ${ }^{[1]}$ with nine million new

\begin{tabular}{|l|l|}
\hline \multicolumn{2}{|c|}{ Access this article online } \\
\hline Quick Response Code: & \\
\hline & Website: \\
\hline & www.ijri.org \\
\cline { 2 - 3 } & DOI: \\
\hline D. & $10.4103 / 0971-3026.113615$ \\
\hline
\end{tabular}

cases and two million fatalities per year. ${ }^{[2]}$ Approximately $95 \%$ of cases occur in developing countries. ${ }^{[1]}$ In India, more than 1000 lives are lost every day due to TB despite the availability of modern diagnostic aids and treatment. ${ }^{[3]}$

The resurgence of TB has been noted in both endemic and non-endemic regions, mainly due to increased migration, the human immunodeficiency virus (HIV) pandemic, ${ }^{[4]}$ and the emergence of drug-resistant strains of Mycobacterium tuberculosis (MTB). ${ }^{[1,5,6]}$ A relative increase in extra-pulmonary TB has been reported due to a significant decline in pulmonary tuberculosis (PTB) and an only modest decline in extra-pulmonary $\mathrm{TB} .{ }^{[7]}$ 
The genitourinary tract is a primary target of hematogenous infections ${ }^{[8]}$ and is the most common site of extra-pulmonary $\mathrm{TB},{ }^{[9]}$ comprising $14-41 \%$ of the same. ${ }^{[10,11]}$ Genitourinary tuberculosis (GUTB), a term coined by Wildbolz in $1937,{ }^{[12]}$ is a worldwide disease, but shows a more destructive behavior in developing countries. The kidney is the most common site of GUTB. An increased incidence of extra-pulmonary TB has been noted in acquired immunodeficiency syndrome (AIDS).$^{[13]}$

Worldwide, $15 \%$ of TB patients are co-infected with HIV, and in HIV-endemic areas, as many as $75 \%$ of patients with GUTB are co-infected with HIV. ${ }^{[14,15]}$ Hence, HIV-positive patients should be tested for TB, and patients with newly diagnosed TB should be assessed for HIV infection. ${ }^{[16]}$ In fact, with the improving survival rates of AIDS patients, we can expect an increase in the incidence of urinary tract TB. ${ }^{[6]}$

\section{Patient Population}

GUTB usually affects adults between the second and fourth decades of life and is reported as being rare in children ${ }^{[17]}$ and in the fifth and sixth decades. A mean age of 40.7 years (range: 5-90 years) has been noted..$^{[8]}$ There is often a long latent period (5-40 years) between the original pulmonary infection and the appearance of clinical renal disease, ${ }^{[6]}$ which is probably why renal involvement is rare before the age of 20 years.

The youngest reported case of urinary tract tuberculosis (UTB) was 2 years old. ${ }^{[18]}$ In India, it is not uncommon to see children with UTB. We have seen TB autonephrectomy in a-six year old girl.

\section{Symptoms}

UTB has an insidious onset, no specific symptoms and atypical presentations, ${ }^{[16]}$ which lead to difficulty and delay in diagnosis. ${ }^{[1,9,19-21]}$ Most patients present with local symptoms such as frequent voiding; dysuria; ; ${ }^{[21]}$ pyuria; ${ }^{[17]}$ back, flank, or abdominal pain; ${ }^{[22-24]}$ and microscopic or macroscopic hematuria. ${ }^{[17]}$ Systemic symptoms of fever, weight loss, and anorexia are less common. ${ }^{[17,22-24]}$ Hematuria and culture-negative pyuria may be seen at urine analysis. ${ }^{[25]}$ Urine analysis of sediment from a 24-hour specimen for acid-fast bacilli (AFB) is positive in $80-90 \%$ of cases of TB. Urine culture requires 6-8 weeks for diagnosis and there is a $10-20 \%$ false-negative rate. ${ }^{[19]}$ Laboratory findings do not reveal the site or extent of disease, knowledge of which is imperative for further management. Imaging thus plays a major role, both in the initial workup as well as during follow-up.

A negative chest radiograph and tuberculin test cannot exclude the diagnosis of extra-pulmonary TB. ${ }^{[9]}$ Only $36.5 \%$ of patients with UTB have a previous diagnosis of TB, or abnormal imaging studies. ${ }^{[8]}$ Evidence of active TB or an abnormal chest radiograph is present in less than $50 \%$ of cases. ${ }^{[6,7]}$ Only $20-30 \%$ of UTB patients will have a previous history of PTB; an additional 25-50\% will have radiographic evidence of prior subclinical PTB. ${ }^{[16,26]}$

This article reviews the imaging findings on the basis of which an accurate non-invasive diagnosis of renal TB can be made.

\section{Pathogenesis}

Causative organisms

MTB, an obligate pathogen, is the usual cause, occasionally, Mycobacterium bovis, ${ }^{[27]}$ and Mycobacterium avium intracellulare (MAIC). MAIC is transmitted via natural water sources, indoor water systems, pools, and hot tubs, ${ }^{[28-30]}$ and can cause disseminated disease, particularly in immunosuppressed individuals, including renal transplant patients. ${ }^{[31]}$

\section{Spread of tuberculosis to the urinary tract}

Hematogenous dissemination of MTB occurs from a primary TB focus within the lungs, bone, or other organs and can involve both kidneys. ${ }^{[32]}$ Bacille Calmette-Guerin (BCG)-a live, vaccine strain-can cause renal lesions via reflux, in $0.1 \%$ of patients undergoing intravesical instillation of BCG for the treatment of bladder cancer. ${ }^{[3,34]}$

Spread of infection at the time of primary tuberculosis During the primary infection, alveolar macrophages phagocytose one or more mycobacteria lodged within an alveolus. Because of their high resistance to destruction, these virulent mycobacteria multiply within the macrophages, which may eventually result in lymphatic and hematogenous dissemination, with seeding of tubercular bacilli throughout the body. ${ }^{[35]}$ The bacilli have stringent growth requirements and generally tend to proliferate only at a few sites, the kidney being one. ${ }^{[27]}$

The kidneys, and possibly the prostate and seminal vesicles, are often the primary sites of GUTB. All other genital organs, including the epididymis and bladder, become involved by ascent or descent of MTB from a source elsewhere in the genitourinary tract. ${ }^{[9]}$ In most patients, acquired cellular immunity develops and there is inhibition of bacterial multiplication and containment of the disease by the formation of microscopic granulomas ${ }^{[35]}$ Healing may also occur as a result of anti-TB chemotherapy administered to control the clinically active focus.

In immune-competent patients, these granulomas heal or remain stable for many years. ${ }^{[36]}$ As they usually do not exceed $3 \mathrm{~mm}$ in diameter, ${ }^{[37]}$ they are difficult to visualize and may be missed unless carefully looked for. 
Re-activation of tuberculosis

If there is a breakdown in host immunity, re-activation or re-infection occurs. It has been reported that a reduction in serum 25-OH-vitamin D levels leads to fall in cell-mediated immune defenses, which can result in activation of latent tuberculosis. ${ }^{[37,38]}$ Hence, it would be worthwhile checking and restoring 25-OH-vitamin D levels in malnourished individuals with TB.

One or more tubercles may enlarge after years of inactivity. ${ }^{[39]}$ This latent period varies considerably and may extend from 5 to 40 years. ${ }^{[22,25]}$

In the kidneys, the bacilli lodge in the periglomerullar capillaries where they form microscopic granulomas, which may later grow into macroscopic granulomas. ${ }^{[39]}$ This occurs bilaterally.

The morphology of the lesions depends on the site of infection, the virulence of the organism, and the immune status of the patient. ${ }^{[40]}$ In immune-competent patients, granulomas are well formed and caseous necrosis is frequently seen. Various types of tuberculous involvement can occur in different areas of the same kidney, ${ }^{[41]}$ or even in both kidneys. However, severe affection is more commonly unilateral. This is one possible cause of delay in patient presentation, leading to irreparable unilateral loss of renal function.

\section{Parenchymal changes}

The medullary portion of the renal parenchyma is usually spared initially. For unknown reasons, the upper and lower poles of the kidney are more commonly affected than other areas. $^{[17]}$ Cortical granulomas enlarge and coalesce, with the bacilli spilling down the nephrons and getting trapped in the narrow segment of the loop of Henle, establishing new foci of infection within the renal pyramid. These papillary lesions caseate and cavitate, frequently forming ulcero-cavernous lesions as they erode into the pelvicalyceal system (PCS). ${ }^{[35]}$ Extensive papillary necrosis may develop with the formation of frank cavities and destruction of the adjacent renal parenchyma. These may also extend into the collecting system ${ }^{[2,41]}$ via rupture, or cause parts of the papillae to become necrotic and slough. ${ }^{[41]} \mathrm{A}$ mass lesion may result from massive destruction and coalescence of granulomas, if they do not rupture into the adjoining calyx. ${ }^{[42]}$ Alternatively, these granulomas may coalesce and form cavities after liquefaction. Hypercalcemia may occur, usually secondary to abnormal cortisol production by granulomatous tissue. ${ }^{[43]}$ Although calcification is unusual in the early stages of the disease, nearly every end-stage tuberculous kidney contains calcification. Rarely, UTB can present as a well-circumscribed multi-septated cystic renal mass. ${ }^{[44]}$ In immunosuppressed individuals, the granulomas may be less well formed and caseous necrosis is seen less frequently. ${ }^{[27]}$
Pelvicalyceal system changes

When bacilli are shed into the urine, the disease spreads antegradely to involve the urothelium of the renal pelvis, ureter, bladder and, at times, the adjacent genital tract. ${ }^{[17]}$ Infection in the walls of the calyces, pelvis, and ureter produces significant inflammatory mucosal thickening, a commonly overlooked imaging finding. Single or multiple calyces may be involved in one or both kidneys. Microscopic granulomas may form here too. Ulceration soon follows.

In advanced disease, in addition to loss of parenchyma by caseation, intra-renal scars and strictures lead to obstruction and dilatation of segments of the PCS. Strictures are more common at sites of normal narrowing, such as the calyceal neck, the pelvi-ureteric junction, and the ureterovesical junction. Early scarring is apparently reversible by appropriate steroid treatment, but end-stage fibrotic strictures are irreversible. Urinary obstruction from strictures along with renal parenchymal caseation destroys all or part of the kidney. The pattern of destruction depends on the relative rates of progression of parenchymal disease and urinary-flow obstruction. Parenchymal caseation, necrosis, and calcification may predominate, which causes the kidney to be destroyed [Figures 1 and 2]. Alternatively, obstruction may predominate, in which case massive hydronephrosis or hydrocalicosis may be the final stage. TB of the kidney thus reflects competing processes: (a) The destructive effects of the bacilli, leading to ulceration, cavitation, and fistulization and (b) the host's secondary defense and healing mechanism leading to the formation of granulomas along with fibrosis, calcium deposition, and strictures, which may worsen the obstruction causing progressive renal dysfunction. ${ }^{[26]}$ The final outcome is thus extremely variable. ${ }^{[45]}$

Usually, however, both processes occur concurrently and may lead to a non-functioning, calcified kidney of any size; this process is called autonephrectomy. Nephrectomy has been advised to remove the trapped dormant bacilli in such autonephrectomized kidneys. ${ }^{[46]}$

\section{Tuberculous interstitial nephritis (TIN)}

Occasionally, TB can affect the kidney more insidiously, causing TIN ${ }^{[27,47-49]}$ which, if untreated, progresses to renal failure. Rupture of the bacilli into the interstitium can lead to isolated interstitial disease, without persistent pyuria, hematuria, or identifiable AFB in the urine, leading to diagnostic dilemmas. Histology reveals chronic tubulointerstitial nephritis, usually with granuloma formation, which may or may not be associated with caseation. With appropriate staining, AFB are identifiable on histology. Evidence of coexisting TB elsewhere may be the only clue to TB being the cause of the falling glomerular filtration rate (GFR). If the diagnosis has been made while useful renal function still remains, it may be possible to arrest the fall in GFR or even produce improvement, using a combination 


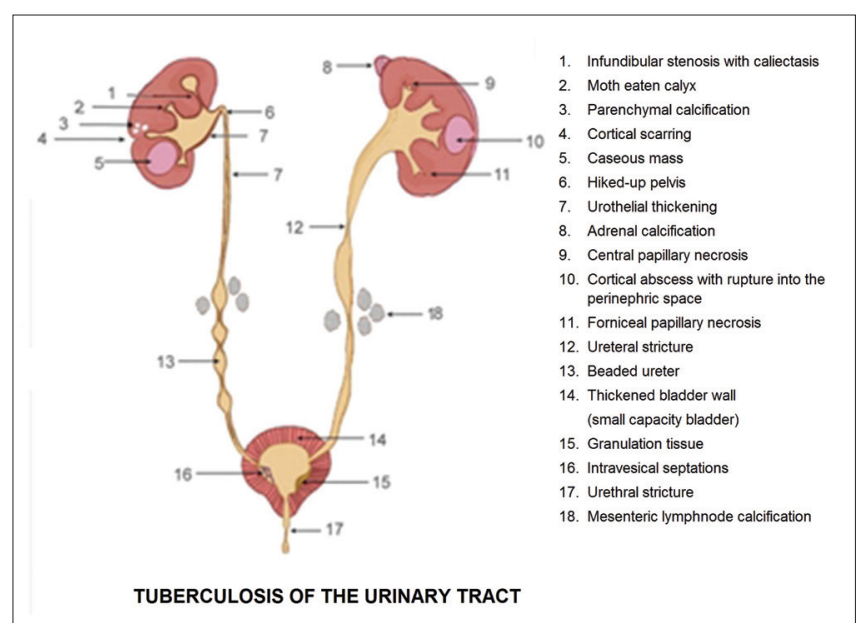

Figure 1A: Diagrammatic representation of the varied effects of tuberculosis on the urinary tract

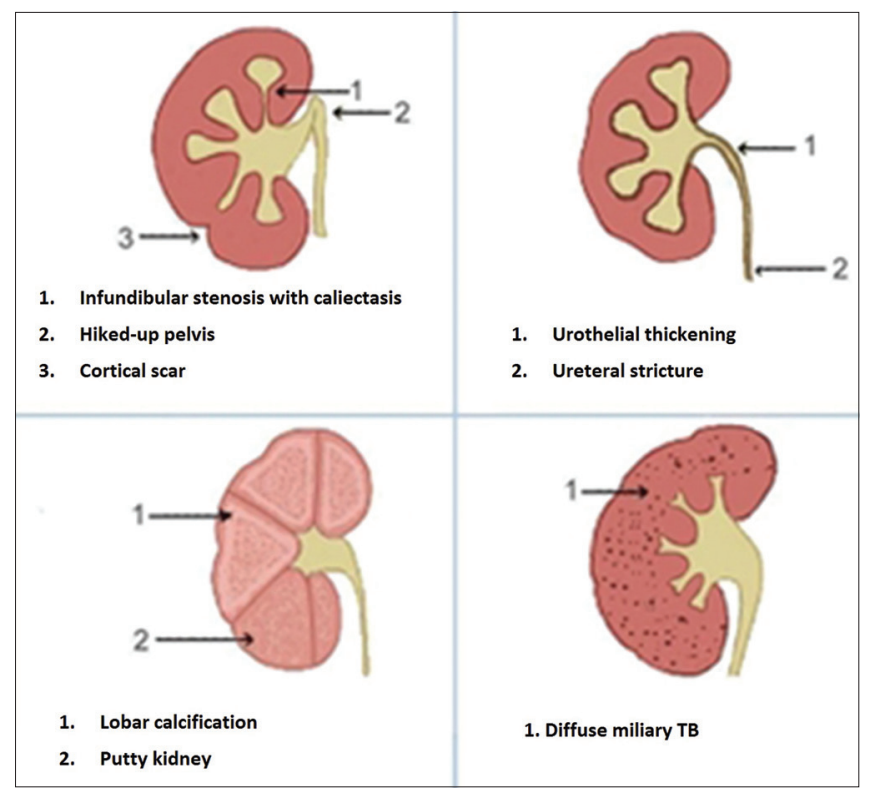

Figure 1C: Diagrammatic representation demonstrating the pathological changes of renal tuberculosis

of anti-tubercular treatment and corticosteroids. ${ }^{[27]}$ TIN has also been reported as a complication of intravesical BCG instillation for bladder cancers. ${ }^{[50,51]}$

\section{Renal failure}

The overall incidence of renal failure reported in the literature is $24 \%$. ${ }^{[52]}$ There are three mechanisms by which TB can cause renal failure:

a. Renal parenchymal infection causing obliterative endarteritis with extensive dystrophic calcification or secondary renal amyloidosis, both leading to renal impairment. ${ }^{[53]}$

b. Post-obstructive atrophy secondary to multiple strictures. ${ }^{[54,55]}$

c. Insidious TIN destroying the renal parenchyma. This is a form of culture-negative renal TB. The only clue could be echogenic kidneys on US along with signs of TB elsewhere.

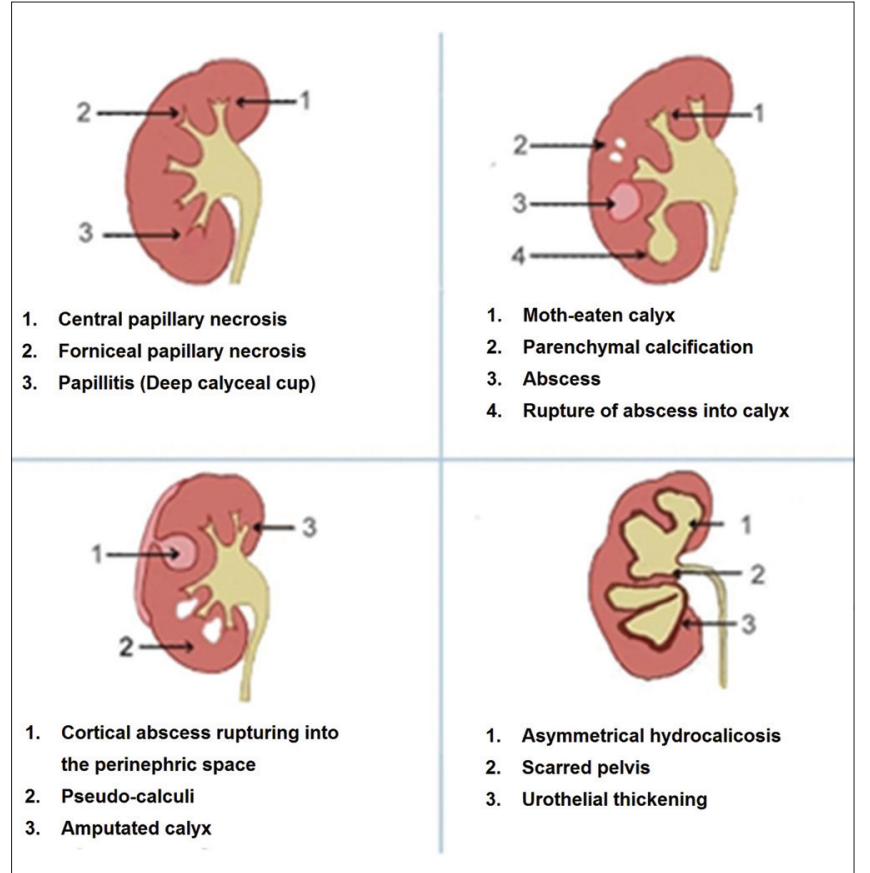

Figure 1B: Diagrammatic representation demonstrating the pathological changes of renal tuberculosis

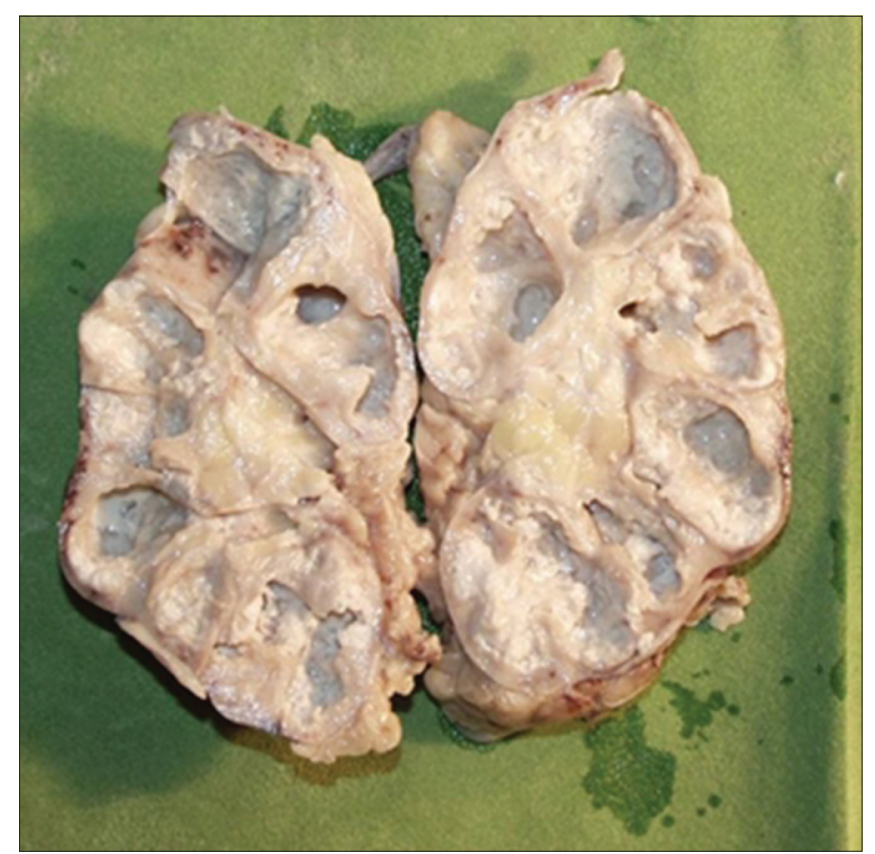

Figure 2: Pathology specimen of end-stage renal tuberculosis: The basis for the 'lobar caseation pattern' is evident

Confirmation is usually by AFB staining of histopathology/ Fine needle Aspiration Cytology (FNAC) samples.

\section{Renal tuberculosis with other renal diseases/lesions}

There have been a number of case reports of TB associated with various forms of glomerulonephritis, ${ }^{[27]}$ including a case report of miliary TB complicated by focal proliferative glomerulonephritis, in which immune deposits were present, but no granulomas. ${ }^{[56]}$ 
Imaging of renal tuberculosis may occasionally be complicated by the concurrent presence of tumors, usually adenocarcinomas, ${ }^{[57,58]}$ although transitional cell carcinoma has also been reported. ${ }^{[59]}$ This association is purely coincidental, although it has been hypothesized that renal tumors may be responsible for reactivation of dormant TB foci. ${ }^{[57]}$ TIN occurring together with leukemic infiltration has also been reported. ${ }^{[60]}$

Renal TB has also been noted in native adult polycystic kidneys, in immunocompromised transplant recipients ${ }^{[61]}$ in association with renal replacement lipomatosis, ${ }^{[2]}$ and in horse-shoe kidneys.

\section{Complications}

\section{Extra renal spread}

The TB disease process may spread to the perinephric and retroperitoneal areas. Fistulas may extend even beyond these confines, including into the gastrointestinal tract, skin, lymphatic vessels, and thoracic cavity (pleura, bronchus). ${ }^{[63]}$ Renal TB causing a liver abscess has been reported. ${ }^{[64]}$

\section{Amyloidosis}

Chronic TB is occasionally complicated by amyloidosis which, in India, is an important cause of renal disease. ${ }^{[65]}$ Prompt treatment of the underlying TB focus can prevent progression to end-stage renal disease.

\section{Squamous metaplasia}

Keratinizing squamous metaplasia, which is a potential risk factor for the development of squamous carcinoma, may develop as a late complication of chronic inflammation and infection of the renal pelvis. ${ }^{[66]}$

\section{Imaging studies}

Imaging findings in renal TB depend upon the extent of the disease process. Familiarity with various imaging features permits early diagnosis and prompt management, thereby reducing patient morbidity. ${ }^{[1]}$ There is a correlation between the timing of the diagnosis and the severity of UTB. ${ }^{[67]}$ Delay in diagnosis may lead to end-stage renal disease, necessitating long-term dialysis. ${ }^{[68]}$

Although it is usually stated that imaging studies are only suggestive of the disease and should not be used for the confirmation or exclusion of UTB, ${ }^{[18]}$ with sufficient experience, one can confidently diagnose UTB on the basis of the imaging findings alone.

The intravenous urogram (IVU) remains the gold standard in imaging early renal TB. Ultrasonography (USG), computed tomography (CT), and magnetic resonance imaging (MRI) lack the spatial resolution necessary to demonstrate the fine erosive changes that affect the urothelium. ${ }^{[69]}$ However, each imaging modality has its own strengths and even the simple plain film has much to offer.

\section{The plain radiograph}

Although UTB most commonly results from hematogenous spread of a pulmonary focus, the chest radiograph will be negative in half. ${ }^{[70]}$ In the other half, there is evidence of healed/active pulmonary disease. ${ }^{[17]}$ However, only $10 \%$ of radiographs show signs of active PTB. ${ }^{[39,71]}$ Extra-pulmonary manifestations such as calcification of lymph nodes, adrenals, prostate, seminal vesicles, or vas deferens; psoas abscesses; calcified granulomas in the liver or spleen; as well as spinal abnormalities, may noted..$^{[17,26,72]}$ These additional findings lend support to the diagnosis of renal TB.

Radiographic identification of calcification associated with renal TB is becoming less common. It is noted on conventional radiography in $24-44 \% .{ }^{[70]}$ It may be the first sign that TB is present. ${ }^{[73]}$ Fine calcifications that were previously unidentifiable are now much better seen with CT. ${ }^{[69]}$ Although calcification is unusual in the early stages of the disease, nearly every end-stage tuberculous kidney contains calcification. Renal calcification can take a variety of patterns, varying from few minute areas of calcification to a complete cast of the kidney. Initially, the calcifications are faint and punctate, but eventually coalesce. ${ }^{[19,51]}$ Early calcification may be amorphous, granular, or curvilinear, occurring typically within the renal parenchyma. ${ }^{[9,74]}$ Focal globular calcification involving a renal lobe is frequently associated with a granulomatous mass. ${ }^{[70]}$ Triangular ring-like calcifications that are characteristic of papillary necrosis may be noted within the collecting system. ${ }^{[75]}$ Calcified caseous tissue characteristically appears to be very homogeneous and only moderately dense, looking like ground glass; this is often referred to as 'putty kidney' Premkumar et al. ${ }^{[76]}$ labeled calcification 'putty-like' if any area of faint calcification of uniform density was greater than $1 \mathrm{~cm}$ in diameter. ${ }^{[76]}$ A lobar pattern of calcification, with calcific rims outlining the periphery of distorted renal lobes, is pathognomonic of $\mathrm{TB}^{[41]}$ [Figure $3 \mathrm{~A}$ and $\mathrm{B}$ ]. This occurs in far-advanced renal TB, accompanied by autonephrectomy. As TB often independently involves each lobe of the kidney, renal destruction takes place lobe by lobe. ${ }^{[39]}$ Hydrocalicosis combined with caseation pushes the residual normal renal parenchyma peripherally. As calcification occurs at the boundary between necrotic and viable tissue, the appearance is that of lobar rims. ${ }^{[39]}$

Gow $^{[46]}$ believed that calcification in renal TB has an unfavorable prognosis and, if left alone, would result in an increase in the size of the calcification and deterioration of renal function. Renal or ureteric calculi have been noted in up to $19 \%$ of cases. ${ }^{[70]}$ Apperson et al. ${ }^{[7]}$ emphasized the difficulty of differentiating calcifications from calculi in renal TB. In their cases of renal TB, 9.3\% had discrete calculi and $8.7 \%$ had parenchymal calcification. They also 


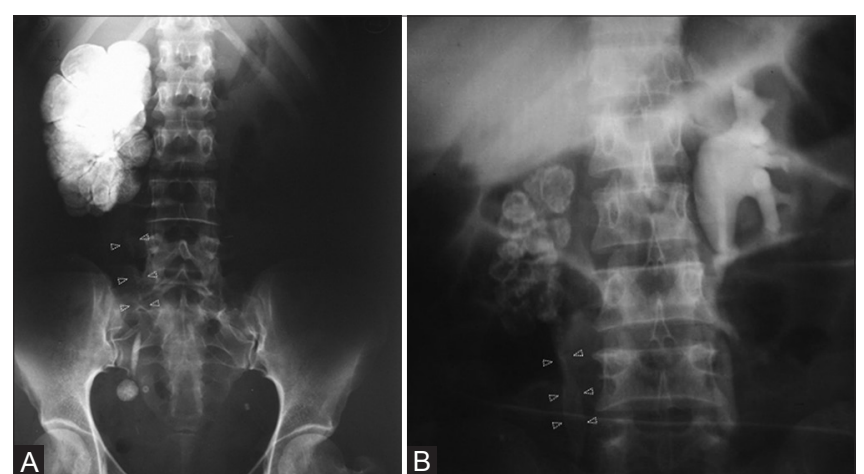

Figure $3(A, B)$ : (A) Plain radiograph revealing classic lobar pattern of calcification, which is pathognomonic of end-stage renal tuberculosis. Ureteral calcification is also noted, which is fainter in upper parts (arrowheads), (B) intravenous urogram revealing the 'classic' lobar pattern of calcification in a non-functioning $(R)$ kidney. (The lobar distribution of calcification is better appreciated in the upper half of the kidney). Ureteral calcification is also noted (arrowheads)

found secondary non-tuberculous infection in one-third of the cases in which calcification or calculi were present. In our opinion, such dense calcification may mimic calculi-'pseudo-calculi' [Figure 4]. Keratinizing squamous metaplasia, a potential risk factor for the development of squamous carcinoma, may develop as a late complication of chronic inflammation and infection of the renal pelvis. ${ }^{[6]]}$ The calcification may extend along the ureter. When this occurs, it is virtually as diagnostic as the lobar pattern of calcification. In fact, the occurrence of any upper ureteral calcification (however, faint) along with any other renal calcification is a good pointer of renal TB.

Soft tissue calcification is seen less often as a sequela of healing than it used to be, and calculus disease is rapidly becoming the most frequent from of calcification associated with renal TB. ${ }^{[69]}$ The authors have seen renal pelvic calculi in renal TB take on odd shapes, and propose that they be labeled 'scarred calculi.' These stones do not conform to the shape that calculi take when formed within a normal renal pelvis. In renal TB, due to pelvic scarring, the shape of the pelvis is deformed, and calculi that form subsequently take on this irregular deformed shape, offering a good clue regarding the presence of renal TB.

Upward-pointing renal pelvic calculi [Figure 5] may be seen, suggesting the presence of a 'hiked-up' pelvis, which is a characteristic urographic finding in renal TB.

Renal imaging studies - Intravenous urography

The IVU has been considered as one of the most useful tests for obtaining anatomical and functional details of the kidneys. ${ }^{[78]}$ It can show a broad range of findings, depending on the severity of infection. In a series of 45 patients, the IVU pointed to the diagnosis of urinary TB in $88 \% .{ }^{[79]}$ However, approximately $10-15 \%$ of patients who present with active renal TB may have normal urographic findings. ${ }^{[25]}$ Isolated parenchymal miliary tubercles usually produce urographic

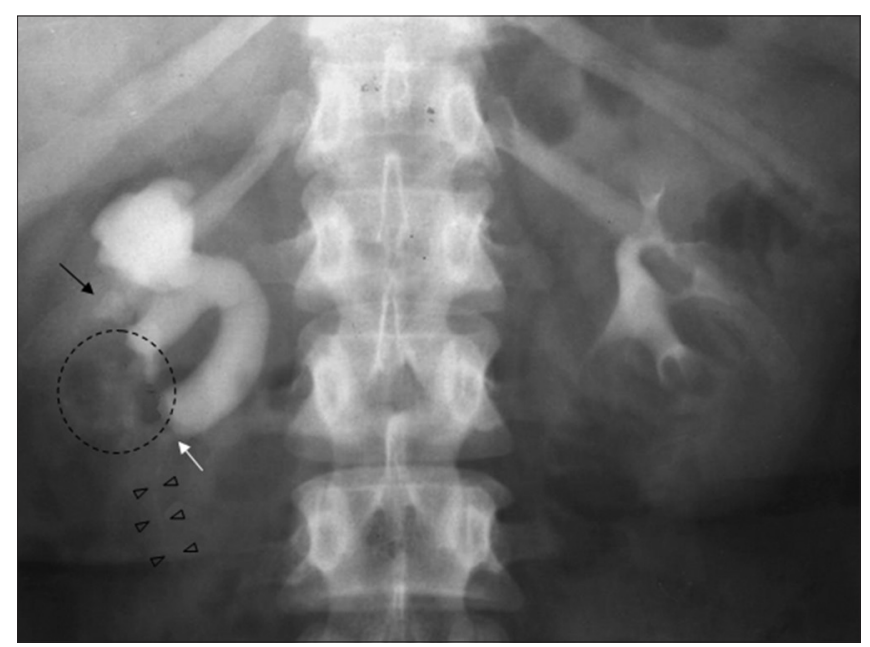

Figure 4: Intravenous urogram revealing a $(R)$ ureteric stricture (white arrow) with ureteric calcification (black arrowheads), pseudo-calculi (black arrow), and irregular calcification in the parenchyma (circled area)

findings only when a calyx is involved. ${ }^{[39]}$ The earliest urographic change occurs in the minor calyces, with subtle initial signs such as minimal calyceal dilatation. ${ }^{[73]}$ and mild loss of calyceal sharpness due to mucosal edema. ${ }^{[39]}$ As the disease progresses, the calyceal outline becomes more irregular, fuzzy, and ragged and, later, feathery and moth-eaten in appearance [Figure 6A-C and 7]. ${ }^{[17,80-82]}$ Although calyceal erosion has been described as the first IVU sign in renal $\mathrm{TB}$, in the author's opinion, in practice, early papillary necrosis may be the first detectable sign. It has been stated that erosion of the papillae from TB is more ragged than that from other causes, ${ }^{[69]}$ but this need not always be true. Caseating parenchymal tuberculomas may rupture into an adjacent calyx, resulting in an irregular cavity that fills with contrast [Figure $8 \mathrm{~A}$ and $\mathrm{B}$ ]; ${ }^{[39,73]}$ according to Elkin, this resembles renal papillary necrosis on IVU or retrograde pyelography. ${ }^{[39]} \mathrm{TB}$ papillary necrosis results not only from ischemia, which is the basis of change in most renal papillary necrosis, but also as a result of direct tissue destruction. We have seen classic early forniceal and even central papillary necrosis in numerous proven cases of renal $\mathrm{TB}$ that cannot be differentiated from papillary necrosis due to other causes. In TB, the central type is probably due to ischemia, and the forniceal, usually due to direct erosion. Ischemic papillary necrosis in renal $\mathrm{TB}$ could be caused by a small granuloma eroding or impinging upon adjacent vessels, ${ }^{[6]}$ or be the result of TB endarteritis. ${ }^{[83]}$ Medullary cavitation with communication to the collecting system has been described as a frequent finding by Kollins et al. ${ }^{[84]}$ It may be the sole radiographic abnormality and, at times, may not be differentiable from papillary necrosis due to other causes. It may involve one or more papillae, unilaterally or bilaterally, and can vary in appearance from small and smooth to large and irregular ${ }^{[84]}$ [Figure 6A-C]. Irregular pools of contrast material may thus be seen adjacent to dilated calyces. ${ }^{[74]}$ Focal or global compromise of renal function may be noted [Figure 9A and B]. 
The abnormalities outlined so far, i.e., calyceal dilatation, loss of sharpness, fuzziness, papillary necrosis, and initial cavitation, are the early changes of renal TB. The late or advanced manifestations include extensive cavitation, fibrotic strictures, cortical scars, mass lesions, calcification,

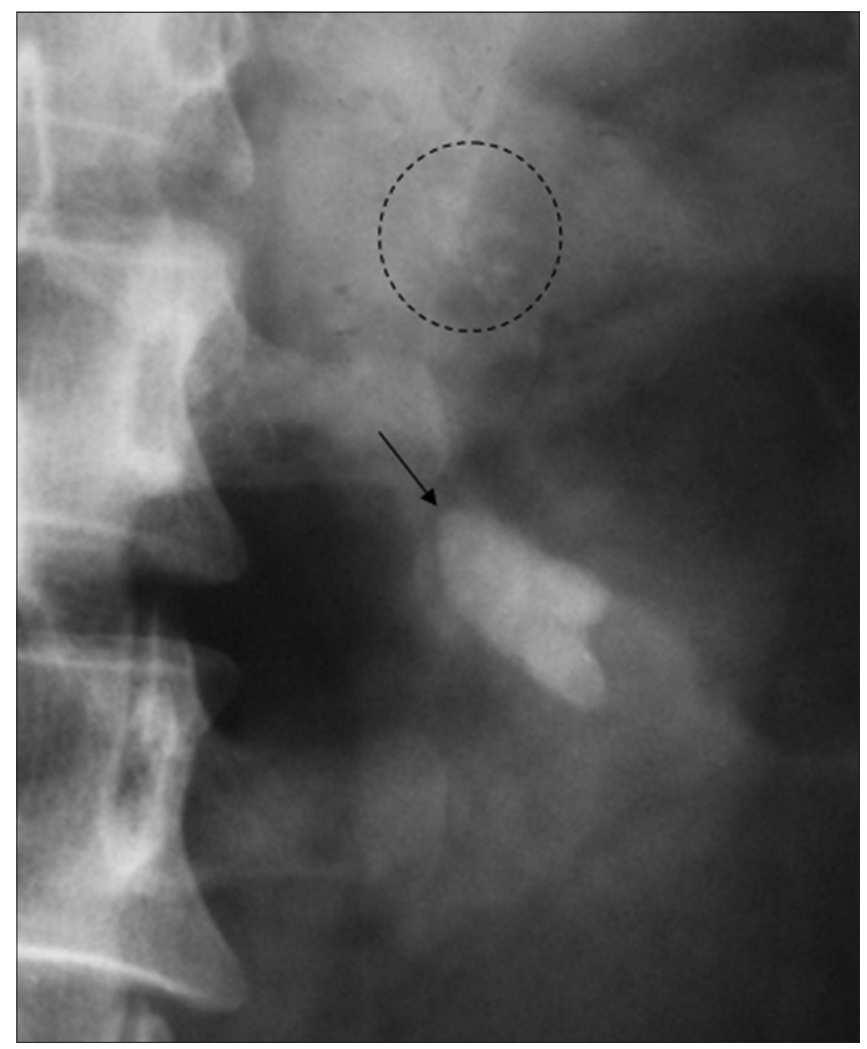

Figure 5: Intravenous urogram revealing an upward pointing (arrow) renal pelvic calculus, suggesting the presence of a hiked up renal pelvis. Multiple discrete calcifications are noted in an upper polar tuberculosis cavity (circled area) autonephrectomy, perinephric abscess, and fistula formation.

\section{Cavitation}

Cicatricial deformity of the calyces may lead to pinching of the tips of the minor calyces. Continued destruction may transform the minor calyx into a large pocket of necrotic caseous material, with or without fibrous obstruction of the infundibulum. ${ }^{[73]}$ Cavities may be differentiated as obstructive or non-obstructive. ${ }^{[85]}$ In the former, contrast medium does not enter the cavity on retrograde pyelography, but vague visualization may occur on the IVU; in the latter, opacification occurs only on the retrograde study [Figure 10], making it difficult to differentiate a dilated, diseased calyx from a cavity that has ruptured into the calyx. The obstructive type needs close follow-up with US. Gentle balloon dilatation may be attempted if the narrowing gets worrisome. Successful antegrade balloon dilatation of tuberculous strictures of the urinary tract has been performed by Kim et al. ${ }^{[86,87]}$ The lipping type of cavity, projecting medially, is considered diagnostic of TB. ${ }^{[88]}$

Renal parenchymal cavitations result from caseation of enlarging tuberculomas. Kidneys with extensive cavitations are referred to as ulcero-cavernous kidneys, and usually do not excrete contrast medium. ${ }^{[36]}$ If the cavity ruptures into the collecting system, pronounced TB bacilluria results, increasing the likelihood of the disease process spreading to other parts of the urothelium, with the possibility of a schirrous reaction that may later cause stenosis and obstruction of the collecting system. ${ }^{[69]}$

\section{Strictures/scars}

Renal functional damage due to strictures is greater
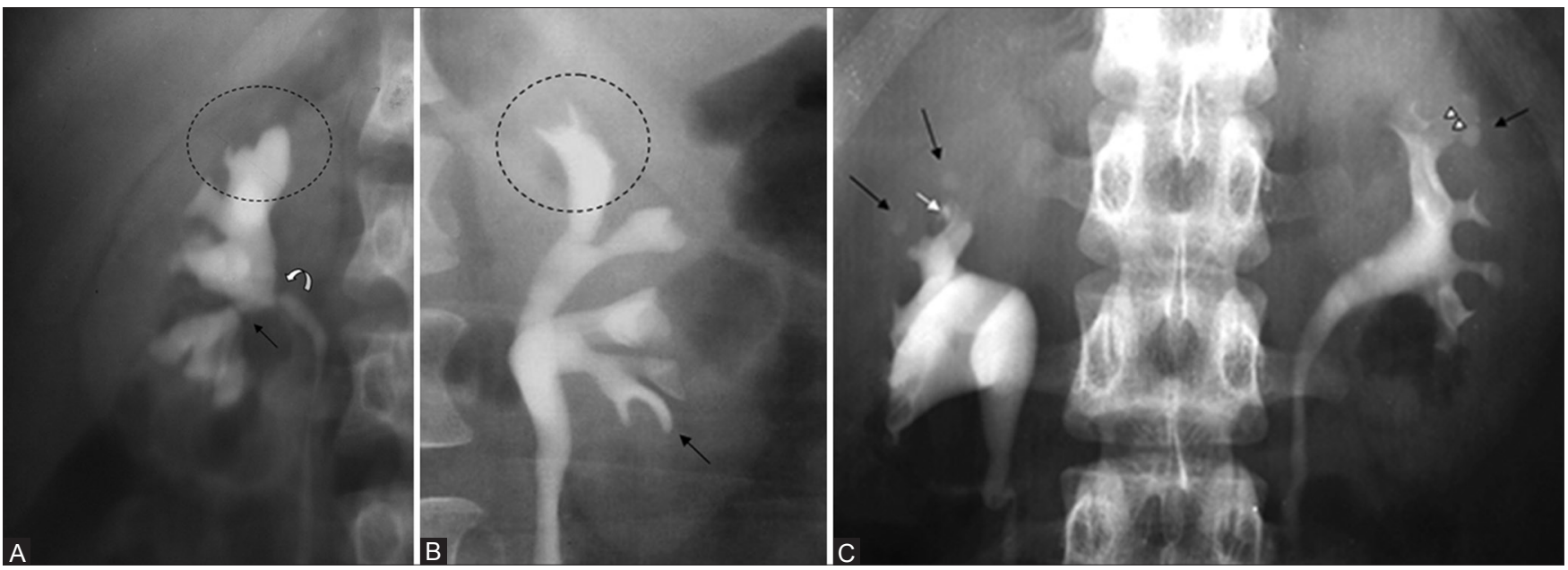

Figure 6 (A-C): (A) Intravenous urogram revealing lower infundibular (arrow) and renal pelvic scarring (curved arrow). Note areas of papillary necrosis in the circled area, (B) Intravenous urogram revealing papillary necrosis in the upper group of calyces, with irregularity of the calyceal margins and the lateral margin of the upper infundibulum (dotted circle), indicating spread of infection from the calyx to the infundibulum. (Healing forniceal papillary necrosis of non-tuberculosis origin noted in a lower calyx (arrow), (C) Intravenous urogram revealing multiple parenchymal cavities (black arrows) with areas of papillary necrosis (white arrow) in the upper group calyces, bilaterally. The (L) upper group (lateral division) calyceal outline is destroyed by adjacent granulomatous tissue (arrowheads) 


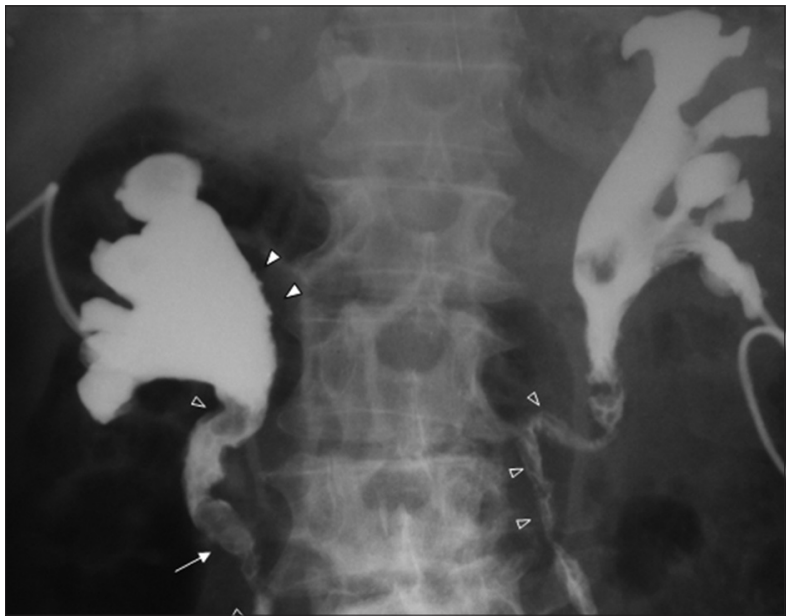

Figure 7: Bilateral percutaneous nephrostomogram revealing multiple filling defects along the upper ureter, bilaterally, representing sumucosal granulomas (empty arrowheads). The large filling defect noted in the (R) ureter is a calculus (white arrow). The high density of the contrast in the collecting systems is obscuring the sumucosal granulomas; however, irregularity along the medial pelvic margin gives a clue to the presence of the same (solid arrowheads)

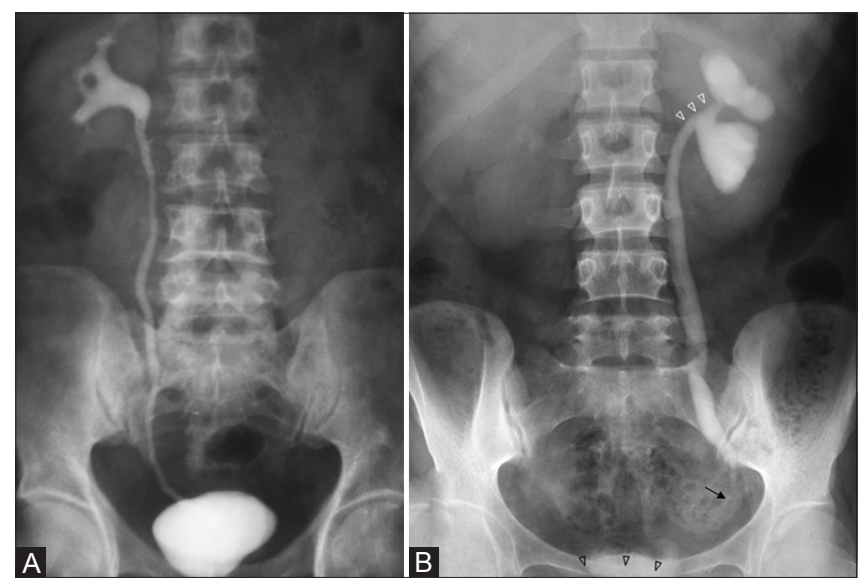

Figure 9 (A, B): (A) Intravenous urogram revealing a non-functioning (L) kidney and a small capacity urinary bladder. The combination is suggestive of a tuberculosis origin for the non-function, (B) Intravenous urogram revealing non-functioning $(\mathrm{R})$ kidney. $(\mathrm{L})$ Renal pelvic and upper infundibular scarring (white arrowheads), resulting in uneven caliectasis. A (L) lower ureteric stricture (arrow) and small capacity bladder (black arrowheads) are also noted

than that from renal parenchymal tuberculomas. ${ }^{[39]}$ The three danger points of fibrosis are: The lower ureter, the pelvi-ureteric junction, and the neck of a calyx ${ }^{[69,73,89]}$ [Figure 11]. Fibrosis is the result of healing and may thus develop during treatment. ${ }^{[39]}$ Strictures may affect the calyceal neck, infundibulum, or the renal pelvis and result in hydrocalyx, regional hydrocalicosis, or generalized dilatation of the calyces and infundibula, respectively. Commonly, a number of strictures are present, and the renal pelvis is small and contracted. Obstruction of areas not directly affected by tuberculous ulcerations and kinking of the renal pelvis can occur due to traction from a strictured infundibulum and parenchymal fibrosis. These
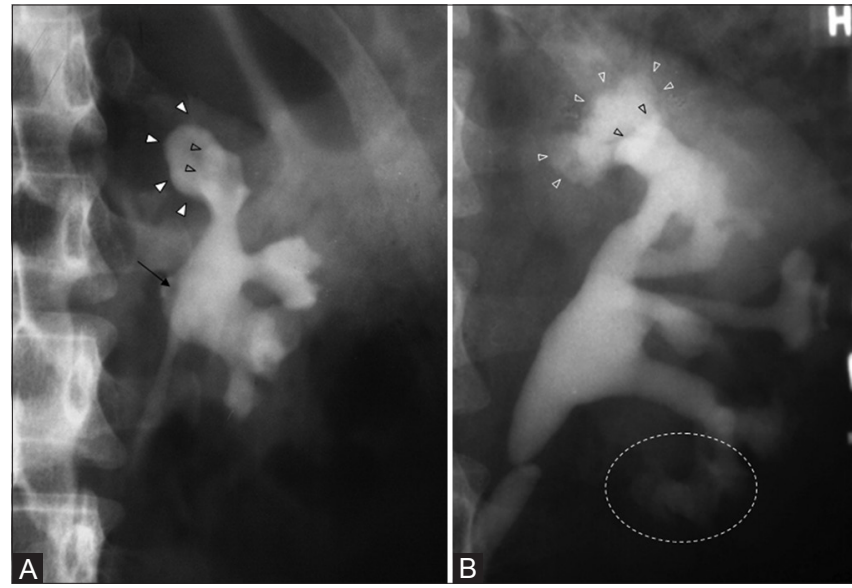

Figure 8 (A, B): (A) Intravenous urogram revealing a "hiked up" renal pelvis (arrow). Tuberculosis cavity (white arrowheads) communicating with the upper group of calyces. Black arrowheads represent medial border of a compound upper calyx, (B) Intravenous urogram revealing fluffy cavities (white arrowheads) communicating with a compound upper calyx (black arrowheads). Odd-shaped pockets of contrast communicating with a lower calyx (and with each other) [circled area], represent caseated necrotic cavities

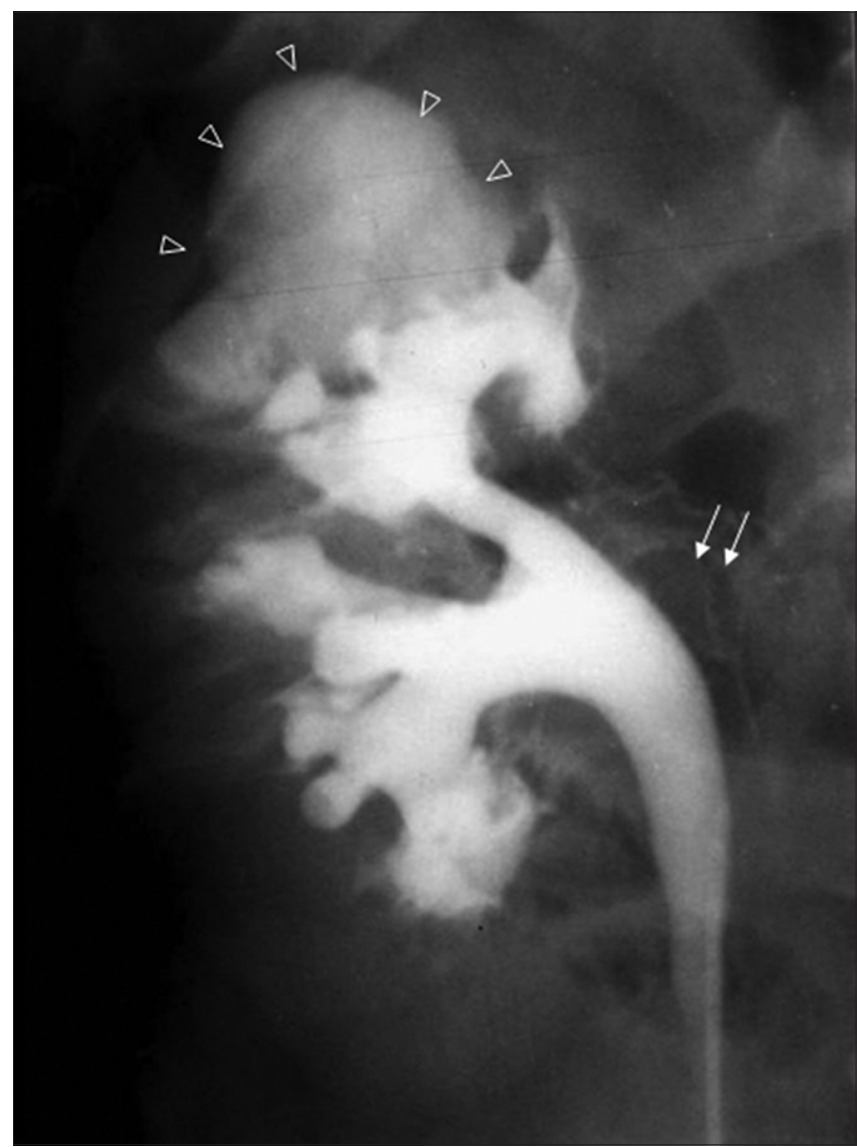

Figure 10: Pyelocavitatory (arrowheads) and pyelolymphatic reflux (arrows) noted on retrograde pyelography

are known as Kerr's kinks. ${ }^{[90]}$ Scarring causes various kinds of calyceal deformities, some of which are probably unique to TB. A stricture of the inferior margin of the renal pelvis 


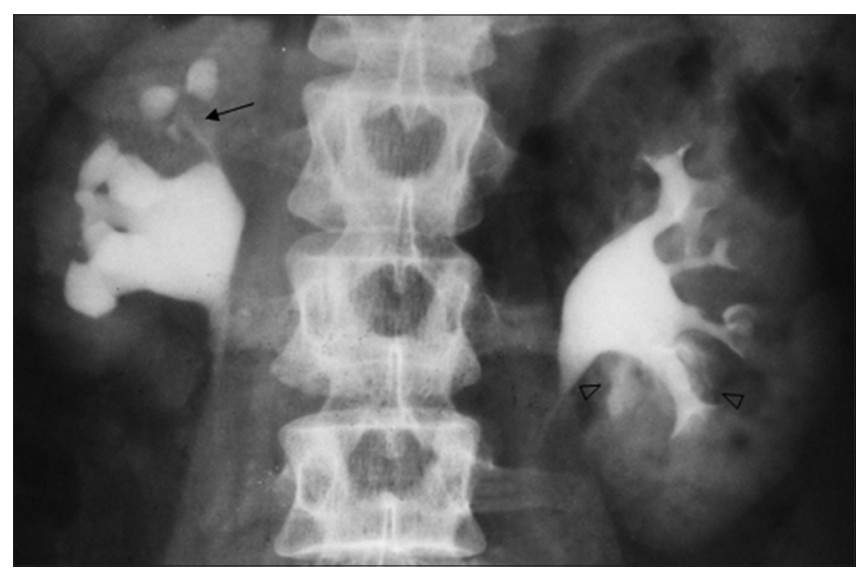

Figure 11: Intravenous urogram revealing right upper infundibular (arrow) and calyceal strictures, with cortical scarring. Pyelosinus extravasation of contrast in the (L) kidney (arrowheads) suggests the presence of fragile calyces

and its cephalic retraction, the so-called 'hiked-up pelvis,' may be seen ${ }^{[69]}$ [Figure 8A].

Obstruction from strictures leads to dilatation of the PCS and pressure atrophy of the renal tissue. Such hydronephrosis tends to have irregular margins and reveal filling defects, which are due to caseous debris ${ }^{[4]}$ [Figure 12]. TB infection in the dilated calyces results in a closed pyocalycosis and leads to caseation of the surrounding renal tissue. A completely stenosed infundibulum or calyx can cause complete failure of contrast excretion by the involved renal parenchyma ('phantom calyx') $)^{[39]}$ [Figure 13]. If such an area is small and represents the only abnormal focus within the kidney, the urogram may erroneously be interpreted as normal. ${ }^{\left[{ }^{11]}\right.}$ A tiny infundibular stump (amputated calyx) or spike may be a good clue in such instances.

Parenchymal scars are common, being seen in over $50 \%$ of patients. ${ }^{[70]}$ They can be seen either overlying blunted calyces or in between the calyces.

\section{Mass lesion}

As the disease progresses it may become difficult to differentiate between hydronephrosis and TB granulomas, as both are masses that do not opacify with contrast at urography/pyelography. US, CT, and MRI are helpful in such situations.

\section{Calcification}

Calcification has been dealt with in detail in the plain film section. The characteristic lobar pattern of calcification should be remembered [Figure 3A and B]. There is an increased incidence of renal calculi and intraparenchymal dense calculi-like calcifications-' pseudo-calculi' ${ }^{.}{ }^{45]}$

Wang et al. ${ }^{[92]}$ noted three imaging patterns in $94 \%$ of IVUs with multiple findings:(a) multiple stricture sites; (b) a

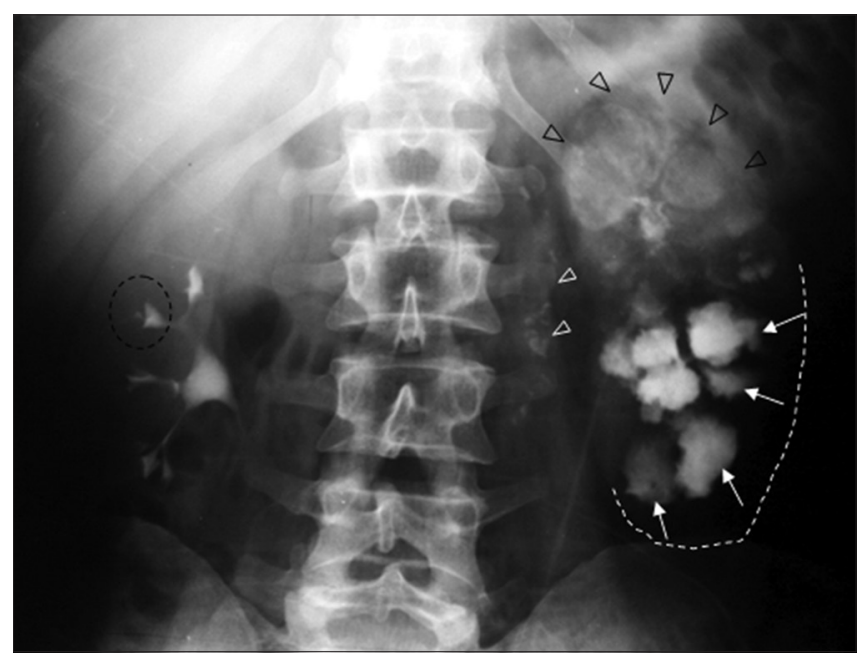

Figure 12: Delayed phase of intravenous urogram with a non-functional (L) kidney opacified retrogradely: Developing lobar caseation in the U/3 of the (L) kidney (black arrowheads). Note assimilation of the dilated calyces into the renal parenchyma. Ragged hydrocalicosis(indicative of marked urothelial thickening) noted in the lower half of the (L) kidney (arrows). Parenchymal demarcation is still clear adjacent to the same (dotted line represents the non-visualized left renal outline). $(R)$ renal papillary necrosis is also seen (circled area) and so are calcified (L) paraspinal lymph nodes (white arrowheads)

single stricture with one other imaging finding; and (c) autonephrectomy with any other imaging finding, barring stricture [Figures 9, 11 and 13].

\section{Autonephrectomy}

The late phase of progression of granulomatous destruction of the kidney, with subsequent obstructive uropathy, can lead to an autonephrectomy. This is considered typical of end-stage renal TB. ${ }^{[69]}$ There are two types: (1) the caseo-cavernous autonephrectomized kidney, i.e., an enlarged kidney converted into a caseous filled sac, with or without calcification; and (2) the shrunken, fibrotic, and often calcified kidney. In both instances, there is usually obstruction of the ureter at some point, but this is not essential in type (1). ${ }^{[73]}$ However, both types will be non-functional on the IVU [Figure 14].

Non-functioning kidneys [Figure 9A-C] in TB can be seen in: (A) autonephrectomy, (B) obstruction (ureteric obstruction, including post-treatment fibrosis), and (C) renovascular hypertension due to renal artery disease in a fibrotic kidney filled with cavities. ${ }^{[73]}$ In (C), autopsy usually reveals conical stenosis or complete obstruction of the renal artery, usually due to medial hypertrophy with intimal or subintimal sclerosis. ${ }^{[73]}$ Surgery (nephrectomy) has been extremely effective in relieving such hypertension. ${ }^{[73]}$

US or CT plays an important role not only in evaluating non-functioning kidneys but also in patients with complications of renal TB. 


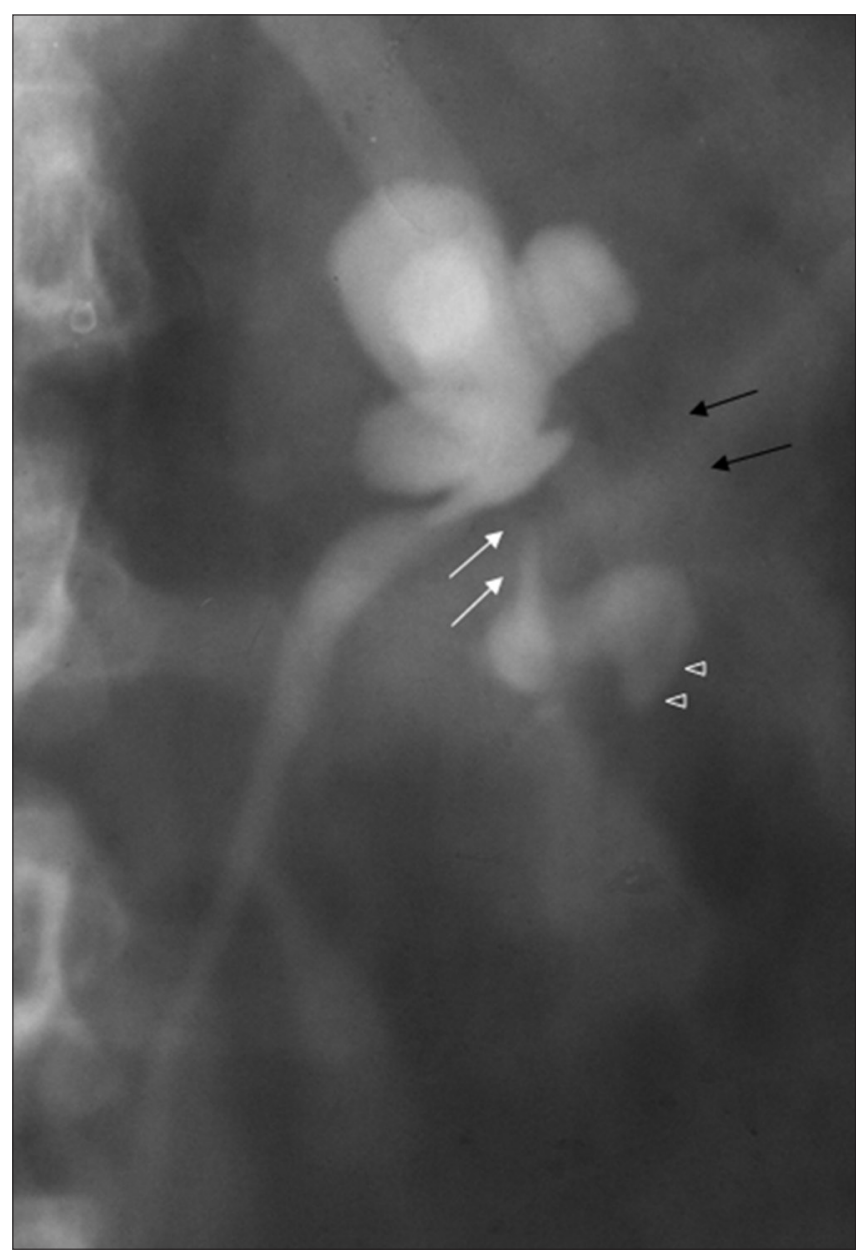

Figure 13: Intravenous urogram revealing cicatrization that has resulted in obliteration of the renal pelvis, multiple infundibular strictures (white arrows) and uneven caliectasis. Note non-visualization of the middle group of calyces-the "phantom calyx" (black arrows) and a cavity communicating with a lower calyx (arrowheads)

The other important complications of renal TB are: (1) perinephritis, (2) perinephric abscess, (3) fistulae, (4) psoas abscesses and, rarely, (5) renal failure.

\section{Perinephric and psoas abscesses}

Tuberculous pyocalicosis, parenchymal abscesses, or pyonephrosis may perforate into the perinephric region to cause perinephric abscess. ${ }^{[77]}$ Renal TB may spread to the psoas muscles via the perinephric space, although involvement from the spine or via a hematogenous route is more common [Figure 15A and B].

IVU features of perinephric abscess include restricted renal movement on comparative deep inspiration and expiration films, or on intentional double exposure films. Those of psoas abscess include lateral renal and ureteric displacement. These are better evaluated on USG, CT, and MRI.

\section{Fistulae and sinus tracts}

Fistulae involving the kidney may communicate with adjoining structures such as bowel, skin, blood vessels, and

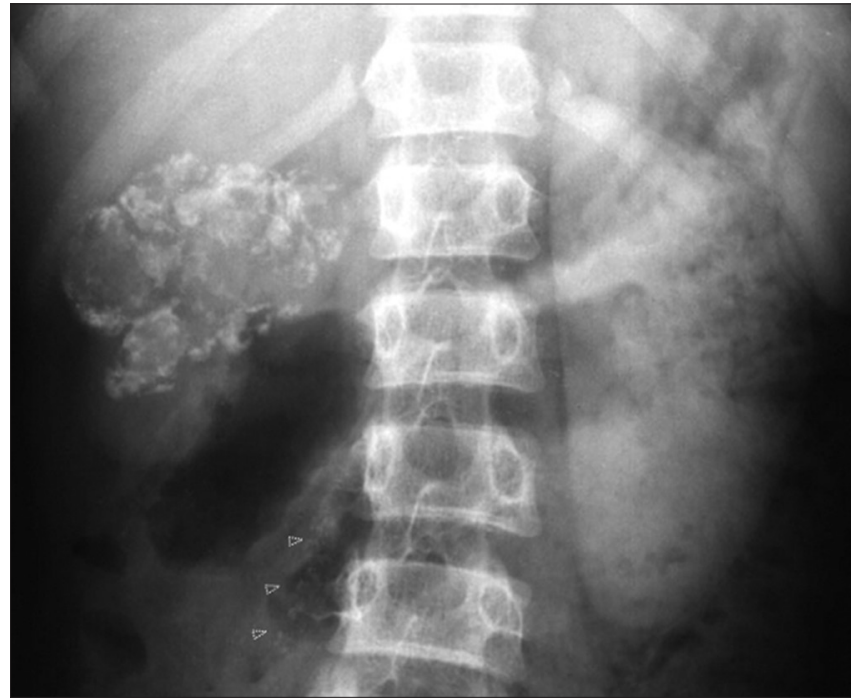

Figure 14: Nephrographic phase of intravenous urogram: $(R)$ subtotal autonephrectomy ("lobar calcification") with partial sparing of the lower pole, which revealed functional calyces on later films. Note scattered calcification in the right psoas region (arrowheads)

lymphatic vessels, as well as the thoracic cavity (pleura, bronchus). ${ }^{[63]}$ Renal fistulas can be classified into those that communicate with the renal collecting system via the parenchyma (reno or nephro) and those that communicate with the renal pelvis (pyelo). ${ }^{[93]}$ Extension of perinephric abscesses to adjacent viscera or tissues results in sinus tracts or fistulae such as nephrogastric ${ }^{[46]}$ pyeloduodenal, ${ }^{[94]}$ nephrocolonic, ${ }^{[85]}$ and nephrocutaneous sinus/fistula.

A fistula leading to the stomach or descending colon originates from the left kidney and that to the duodenum and ascending colon from the right kidney. ${ }^{[39]}$ Such fistulae are uncommon, the nephrogastric type being amongst the least common. ${ }^{[95]}$ Unusual complications also include reno-gluteal fistula. ${ }^{[96]}$

Quite often, urography shows no excretion of contrast from the affected kidney and the diagnosis is established by retrograde pyelography. Rarely, TB of the intestinal tract involves the urinary tract, producing entero-renal and entero-vesical fistulae. ${ }^{[73]}$

Fistulae between the renal collecting system at the fornix and the relatively abundant lymphatic drainage around it have been described. ${ }^{[97]}$ These eventually communicate with the retroperitoneal lymphatic system via the peripelvic system and lead to chyluria. Renal tuberculosis and filariasis are the leading causes of chyluria worldwide. ${ }^{[93]}$ Pyelosinus and/or pyelo-interstitial backflow from a fragile calyx, if accompanied by pyelo-lymphatic backflow, is a useful pointer toward renal TB [Figure 10]. A calyx may be labeled as 'fragile' if it reveals forniceal rupture despite adequate precautions having been taken to avoid excessive abdominal compression during urography [Figure 11]. 


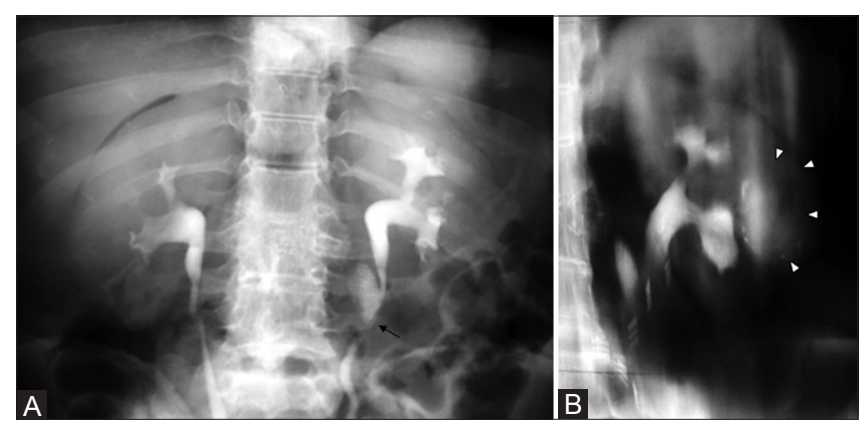

Figure 15 (A, B): (A) Intravenous urogram revealing calcified (L) psoas abscess (black arrow), impinging on the ureter and a calcified caseous renal mass (arrowheads); more apparent on nephrotomography (B)

\section{Renal imaging studies - USG/CT/MRI}

Despite the frequency of UTB, its USG, CT, and MRI features have been described rather infrequently. ${ }^{[13,33,37,53,76,77]}$ These imaging procedures provide valuable information, which cannot be seen on the IVU. ${ }^{[39,92,98]}$ Both USG and CT easily differentiate TB granulomas (seen as solid masses) from hydronephrosis, which is difficult on urography. The non-visualized obstructed system on IVU/retrograde study may show a hydronephrotic/pyonephrotic appearance or a solid 'granuloma' pattern on both USG and CT. ${ }^{[69]}$ The imaging features of TB and non-tuberculous bacterial pyonephrosis are similar. ${ }^{[99]}$

\section{Ultrasonography (USG)}

USG is a readily available technique for demonstrating the various morphologic abnormalities found in renal $\mathrm{TB},{ }^{[35,100]}$ and is a convenient method for guiding needles for FNAC. ${ }^{[101,102]}$ On USG, a mass may be missed if its echogenicity is similar to the renal parenchyma. With diffuse involvement, an 'almost normal kidney' can also be recorded. ${ }^{[69]} \mathrm{A}$ normal sonogram in the presence of a non-functioning kidney is considered typical of TB, although parenchymal infiltration usually causes loss of corticomedullary definition. ${ }^{[100]}$ In the presence of renal/ ureteric colic, this combination of a non-functioning kidney on IVU and a sonographically normal kidney, is most likely to represent sympathetic shutdown following acute calculus obstruction.

It has been stated that USG is less sensitive than IVU or $\mathrm{CT}$ in the evaluation of renal $\mathrm{TB}^{[6,31,83]}$ because of the difficulties in detecting subtle urothelial changes and isoechoic parenchymal masses, relatively less sensitivity to calcifications, inability to evaluate renal function, ${ }^{[25,76]}$ and inability to define the extent of perirenal spread. ${ }^{[45]}$ However, carefully performed USG can show most of the spectrum of morphologic abnormalities in urinary TB. In a large series, USG established the diagnosis in $59 \%$ of cases. ${ }^{[103]}$ Sonographic features in renal TB include parenchymal masses, cavities, urothelial thickening, and calcifications. Two patterns of TB have been described: ${ }^{[76]}$ (a) the more commonly seen infiltrative pattern, with increased echogenicity due to calcifications, infected debris, and/or abscesses; or (b) hydronephrosis or pyonephrosis, with dilated calyces and a small renal pelvis. ${ }^{[104,105]}$ Unfortunately, the demarcation between the two is often not very clear, and the picture is often a combination of both processes.

Each individual finding can also be caused by other disease processes, and the key to correct diagnosis is overall pattern recognition. The distinguishing feature is the visualization of multiple abnormalities involving various sites and the presence of different stages of disease in the same patient. ${ }^{[35,58]}$ Rui et al ${ }^{[103]}$ have attempted to classify the USG features of renal tuberculosis into six types.

The normal renal cortex is homogenous and hypoechoic to the liver and spleen. The medulla can easily be differentiated from the cortex by the presence of the small rounded hypoechoic medullary pyramids adjacent to the bright central echo complex of the renal sinus. Das et al. ${ }^{[32]}$ reported bilateral disease in $30 \%$ of their cases on USG and attributed their improved detection rate to the use of high-frequency transducers that improved tissue characterization, ${ }^{[106]}$ allowing visualization of early focal lesions. This emphasizes the need for careful scanning of the contralateral kidney.

The most frequently encountered sonographic parenchymal abnormality is a focal renal lesion-the parenchymal granuloma. Small $(5-15 \mathrm{~mm})$ focal lesions are either echogenic or have an echogenic border with a central area of low echogenicity, whereas larger focal lesions (>15 mm) have mixed echogenicity and poorly defined borders ${ }^{[32]}$ [Figures 16 and 17]. Granulomas can be better appreciated on color flow imaging, as the 'cut off' of the vasculature highlights the presence of granulomas [Figure 17B]. Masses with cavitation/calcification may also be noted. Vijayraghavan et al..$^{[42]}$ noted masses of mixed echogenicity with multiple punctuate calcifications. Caseation occurring within the masses leads to parenchymal cavities (that can be detected on USG) [Figure 18A-C], which could rupture into the PCS. Occasionally, an appearance like that of 'lobar nephronia' may be noted. Lobar nephronia is usually well delineated and is accompanied by prolonged pain and fever- a clinical finding that is usually only minimal or conspicuous by its absence in tuberculous lesions. Whenever required, an USG-guided FNAC (with culture of the aspirate) may be performed to confirm the diagnosis, especially in patients with negative urine cultures. USG-guided FNAC also aids in defining the nature of sonographically visible lesions in patients with positive urine cultures, ${ }^{[32,102]}$ as TB, acute focal bacterial nephritis (AFBN), xanthogranulomatous pyelonephritis (XPN)[Figure 19], and small benign and malignant tumors may have a similar appearance on USG. ${ }^{[107]}$ Modern laboratory tests such as the polymerase chain reaction (PCR) aid quick diagnosis. The 


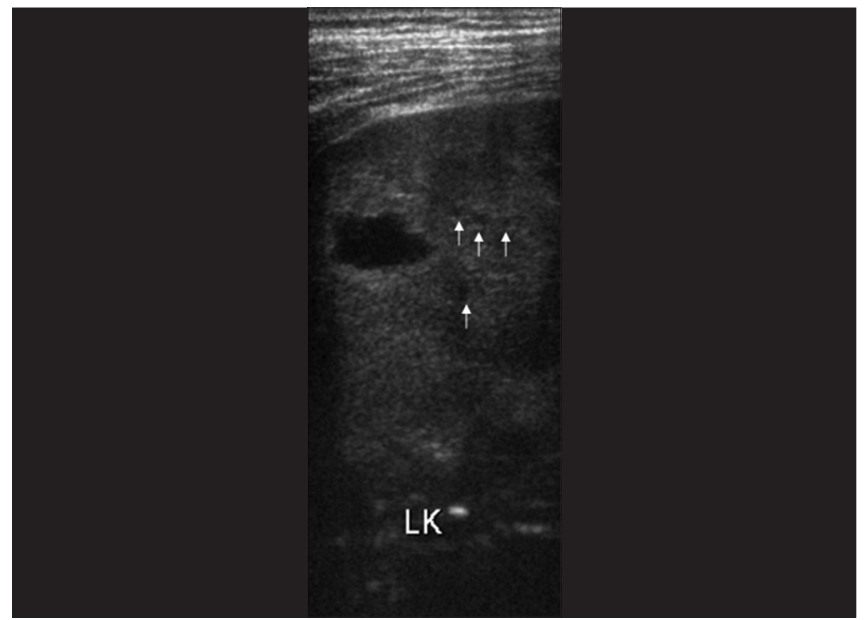

Figure 16: Ultrasonography (USG) - multiple tiny granulomas (white arrows) noted around a caseated tuberculosis cavity in the left kidney, on this high-resolution $(7.5 \mathrm{MHz})$ ultrasound image

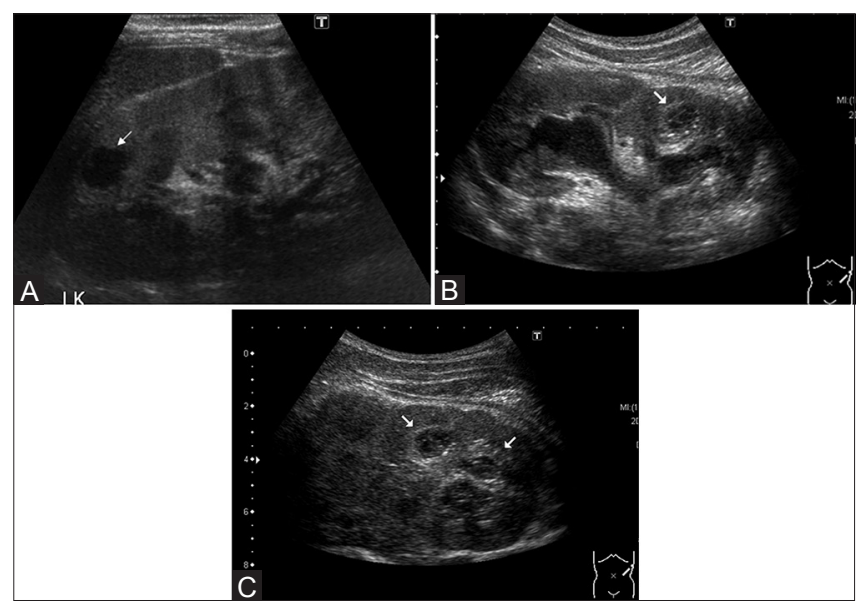

Figure 18 (A-C): (A) High-resolution ultrasound images (acquired with a $7.5 \mathrm{MHz}$ transducer) demonstrate a small irregular caseous cavity (white arrow) in the upper part of the left renal parenchyma, (B) high-resolution ultrasound images revealing a tuberculous cavity with fine septae within, in the lower part of the left kidney of another patient. Note marked urothelial thickening in this dilated system, (C) ultrasonography (USG) image revealing irregular sonolucent cavities, with a semisolid echo texture

high sensitivity and specificity, in addition to the potential for rapid detection of mycobacteria, make PCR (both IS6110:MTB species-specific DNA insertion sequence and 16S rRNA: Mycobacterium genus-specific sequence encoding ribosomal ribonucleic acid) a useful tool in the clinical management of mycobacterial infection in the urinary tract. ${ }^{[108]}$ New PCR based technologies such as cartridge based nucleic acid amplification techniques [CBNAAT] (GeneXpert - Cepheid USA) and Line Probe Assay (LPA) systems, diagnose TB much earlier (in 2 hours and 2 days respectively).

Papillary involvement may be seen as an echogenic non-shadowing medullary mass in close proximity to the calyces, into which it commonly ruptures, to produce a

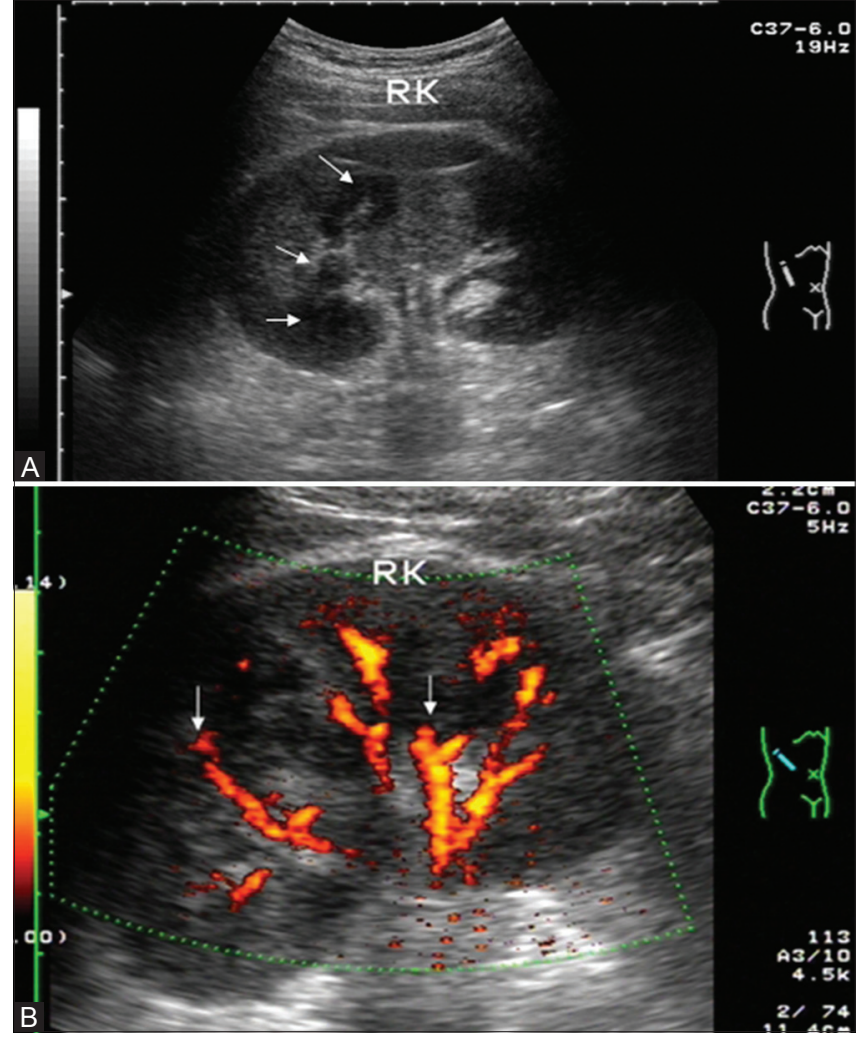

Figure 17 (A, B): (A) Ultrasonography (USG) revealing tuberculosis granulomas of varying sizes (white arrows), (B) Ultrasonography (USG) revealing larger granulomas-the granulomas are highlighted by the vascular "cut-off" (white arrows) noted on this color flow image

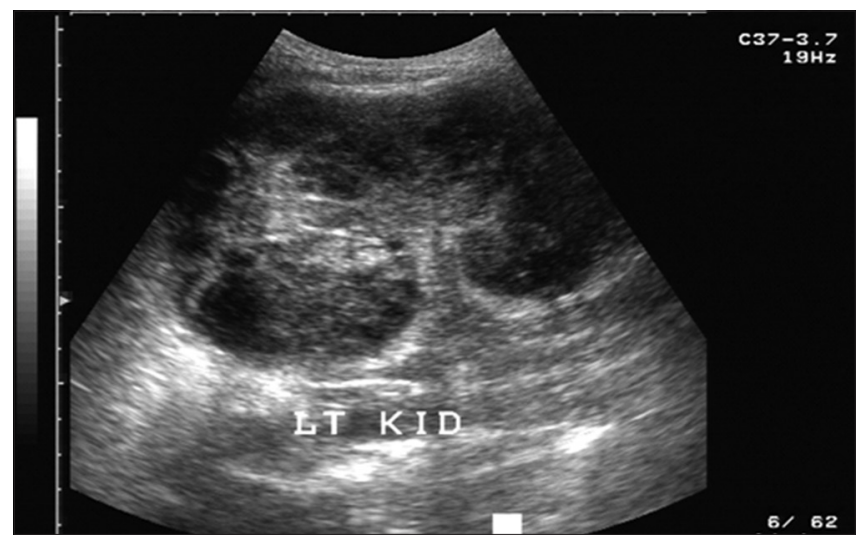

Figure 19: Ultrasonography (USG) image revealing a nxanthogranulomatous pyelonephritis-like appearance in an enlarged tuberculous kidney

cavitatory lesion that communicates with a calyx via a thin or wide anechoic tract [Figure 20A and B]. Its appearance is dependent upon the extent of destruction..$^{[32,42]}$ Sloughing is accompanied by an echogenic flap, which is separated from the calyceal wall. Intracalyceal filling defects may be caused by sloughed papillae as well as blood clots, fungal balls, or other debris; however, other features of renal TB help distinguish the cause. In doubtful cases, FNAC may be performed. ${ }^{[32]}$

Focal caliectasis resulting from infundibular stenosis is 


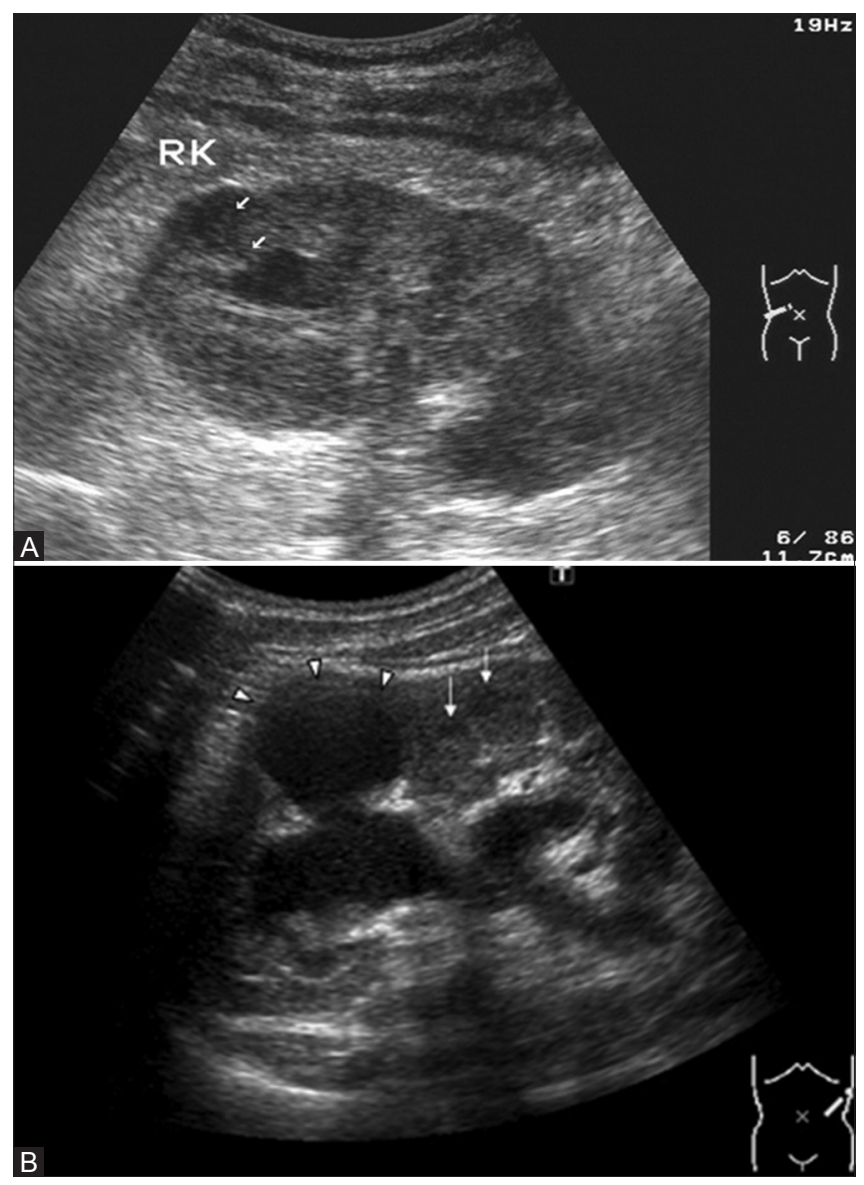

Figure 20 (A, B): (A) Ultrasonography (USG) image revealing a caseating tuberculous granuloma, communicating with a calyx via a narrow tract (white arrows), (B) Ultrasonography (USG) image revealing a large thick walled caseated tuberculous cavity communicating with the upper calyx (arrowheads). Small granulomas noted inferior to this cavity (arrows)

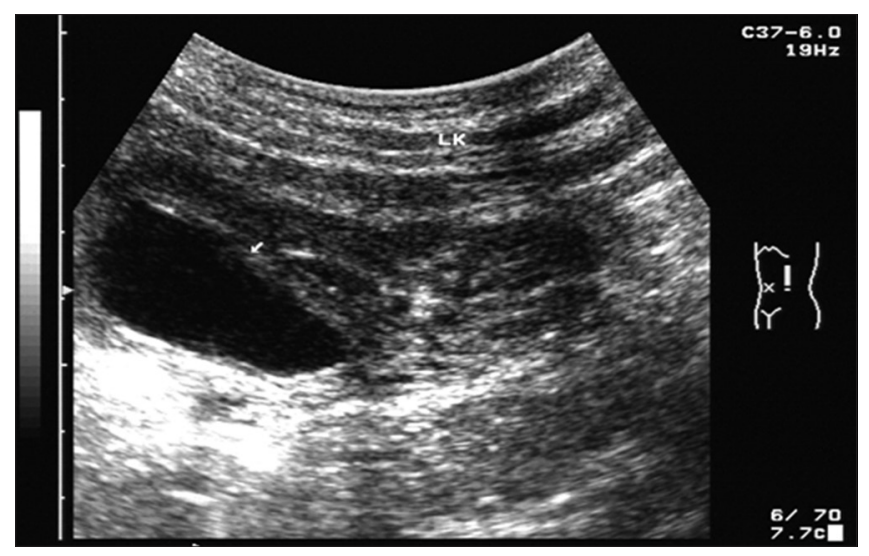

Figure 21: Ultrasonography (USG) image revealing severe focal caliectasis, with moderate urothelial thickening in the upper calyx (white arrow)

frequently encountered [Figure 21], often accompanied by varying degrees of urothelial thickening. This may create a fairly characteristic sonographic pattern of a focally dilated collecting system containing debris. ${ }^{[27]}$ Characteristic uneven caliectasis is seen, which is caused by varying

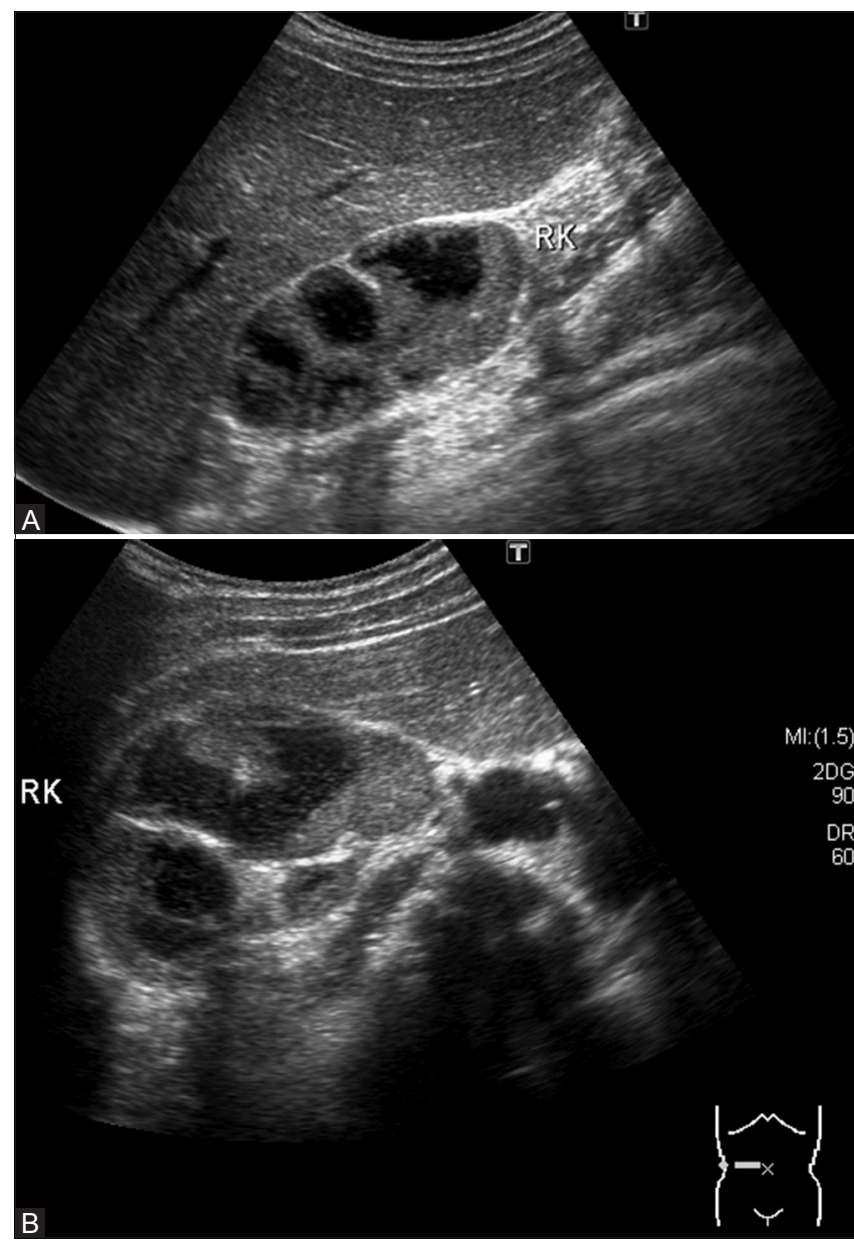

Figure 22 (A, B): (A) Ultrasonography (USG) image revealing uneven caliectasis with ragged urothelial thickening in a tuberculous kidneylongitudinal scan, (B) Ultrasonography (USG) image revealing uneven caliectasis with ragged urothelial thickening in a tuberculous kidney. transverse scan

degrees of fibrosis and obstruction affecting different sites [Figures 22 and 23A-C] $\cdot^{[4,98,109]}$ The accompanying urothelial thickening is quite evident if looked for. When the renal pelvis and ureter are involved by $\mathrm{TB}$, the hydronephrosis becomes severe. ${ }^{[2,21]}$ The pelvis is usually scarred.

This pattern of diffuse uneven caliectasis (without renal pelvic dilatation) accompanied by urothelial thickening, is a good pointer of renal TB [Figure 24A and B], especially in the absence of a renal pelvic calculus.

The renal size is generally maintained. Frank renal swelling is more commonly seen with non-TB infections. However, it is not entirely unknown in renal TB [Figure 19]. A TB renal abscess may be noted as an irregular sonolucent cavity, with a semi-solid echogenicity and a thick ill-defined wall. Necrotic debris and scattered echogenic foci may be noted [Figure 18C]. The renal abscess can extend outward and rupture, leading to a perinephric abscess [Figure 25A and B] and later to a cutaneous fistula. ${ }^{[40,79]} \mathrm{A}$ thorough analysis of the retroperitoneal compartments and, in particular, the 


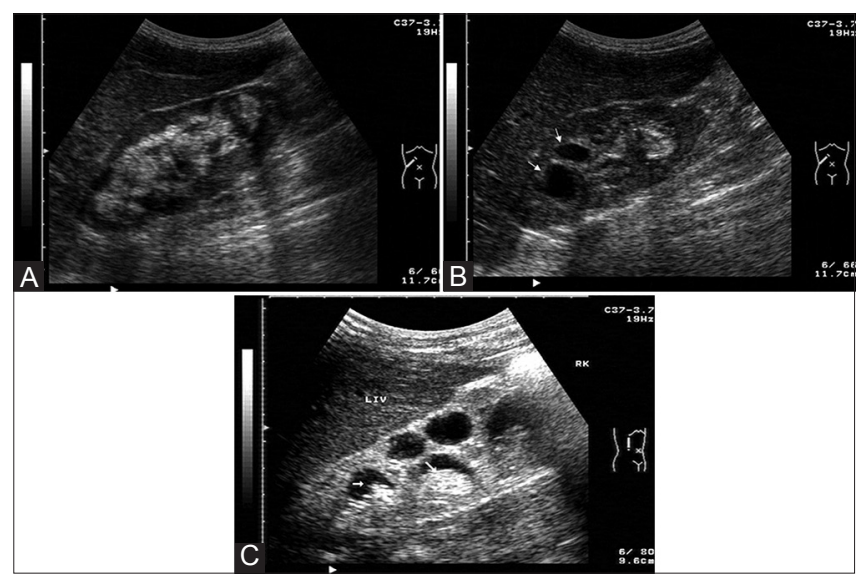

Figure 23 (A-C): (A) Ultrasonography (USG) image revealing hyperechogenic areas of caseation interspersed with the echogenic sinus echoes. (coronal scan), (B) Oblique ultrasonography (USG) scan reveals uneven caliectasis (white arrows) with a hazy interface and urothelial thickening in the upper calyces. The lower calyceal region is replaced by hyperechogenic caseous tissue, (C) Comparative ultrasonography (USG) image of regular (evenly dilated) caliectasis with hyperechoic fungal balls (white arrows) in a HIV-positive patient (note the hyperechogenic material is lying within clearly dilated calyces and are not replacing them as happens in tuberculous caseation)
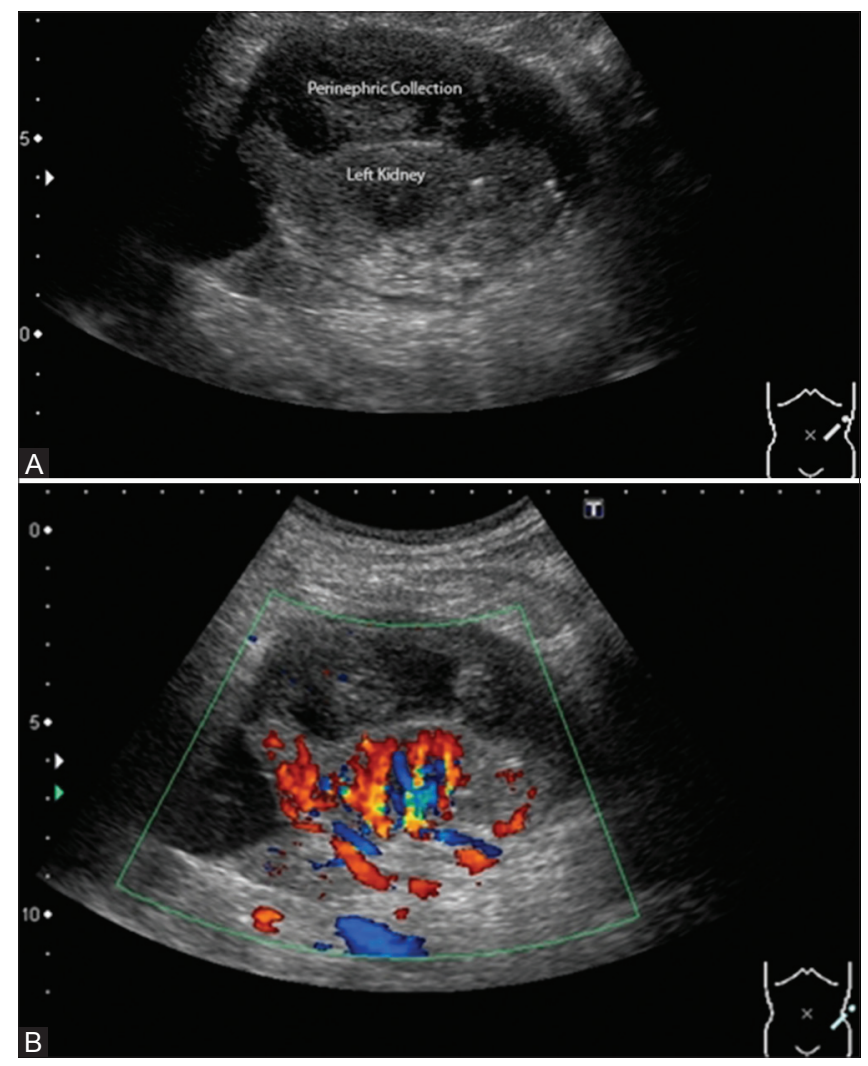

Figure 25: (A) Ultrasonography (USG) image revealing left tuberculous perinephric collection due to a ruptured upper polar tuberculous abscess. (A) Grey scale image, (B) Ultrasonography (USG) image revealing left tuberculosis perinephric collection due to a ruptured upper polar tuberculous abscess. Color flow image revealing lateral extent of the renal parenchyma
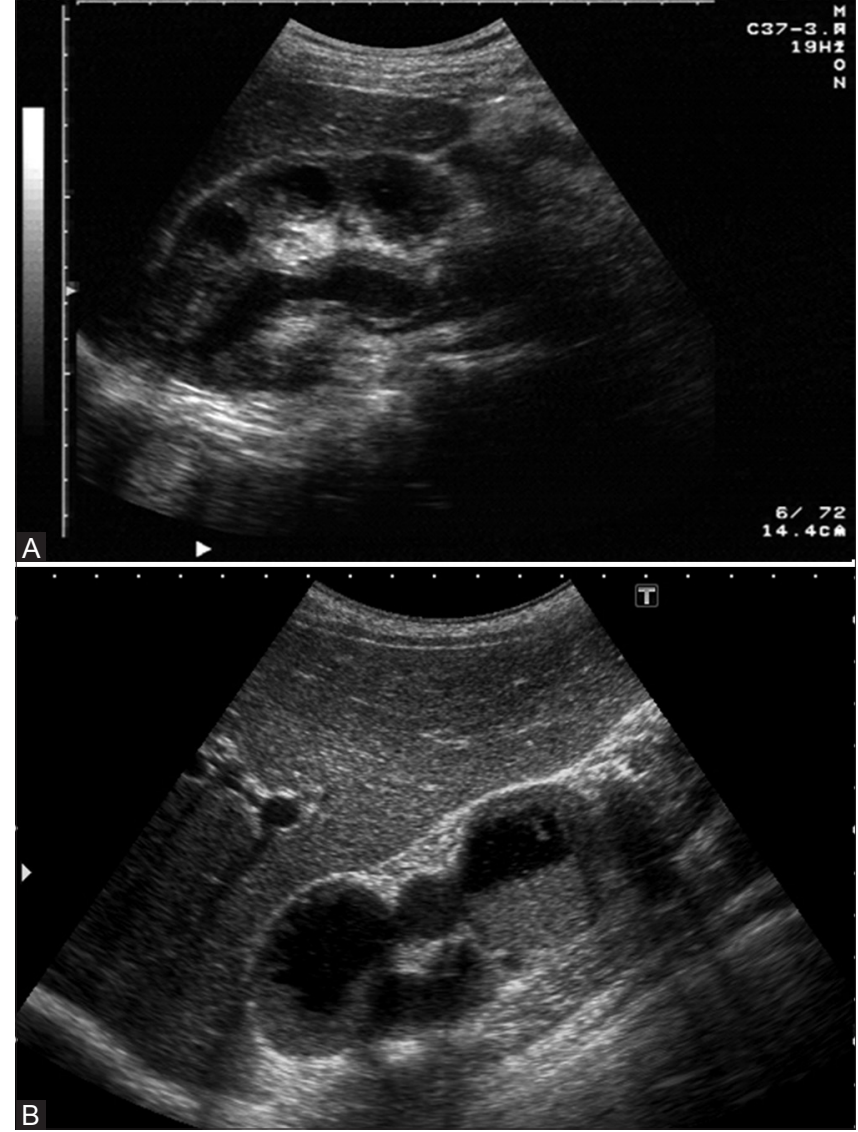

Figure 24: (A) Moderate-to-severe urothelial thickening noted throughout the visualized urothelium. This is well visualized on account of the dilatation due to a tuberculous ureteric stricture, (B) ultrasonography (USG) image revealing uneven caliectasis with ragged urothelial thickening (arrowheads). Note significant debris in the lower calyces

psoas muscle sheath, is required as these are possible sites of a migrating abscess. Restriction of renal movement is a good USG pointer toward perinephric spread. We have seen a case where frank renal swelling was noted along with diffuse spread to the perirenal and posterior pararenal spaces, resulting in innumerable multiseptated collections therein. USG, being a rapid, dynamic, and safe modality, can also be used to detect the presence of TB elsewhere in the abdomen. Findings of omental caking, especially in conjunction with septated ascites and peritoneal, mesenteric, or bowel wall thickening and lymphadenopathy, are virtually diagnostic of abdominal TB. ${ }^{[110]}$

Evolutive multifocal TB also gives rise to diffuse heterogeneous changes, with both parenchymal and central architecture being altered [Figure 26]. Fluid-filled cavities are seen, corresponding either to dilated calyces, or to TB abscesses. When diffuse, the abnormalities are rather similar to those brought about by extensive diffuse urothelial tumors. ${ }^{[99]}$ Caseation is fairly well recognized on USG once one is aware of its pattern [Figure 27A]. Color flow imaging 


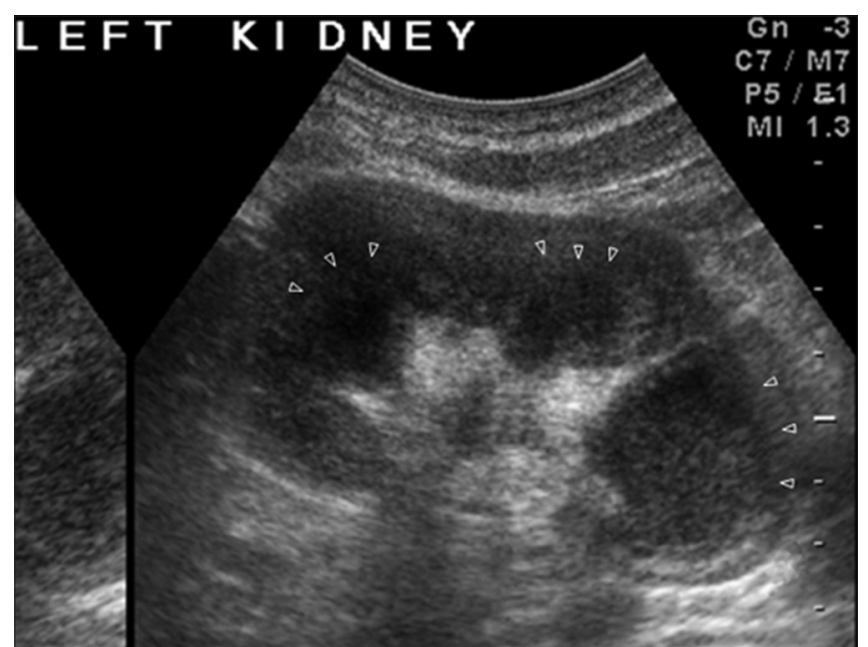

Figure 26: Ultrasonography (USG) image showing evolution of tuberculous lobar caseation. Different phases of destruction are apparent. (Lower group calyces are completely merged with the parenchyma, midgroup calyces about to merge, and upper ones almost merged). Arrowheads demarcate the junction between residual parenchyma and the dilated calyces

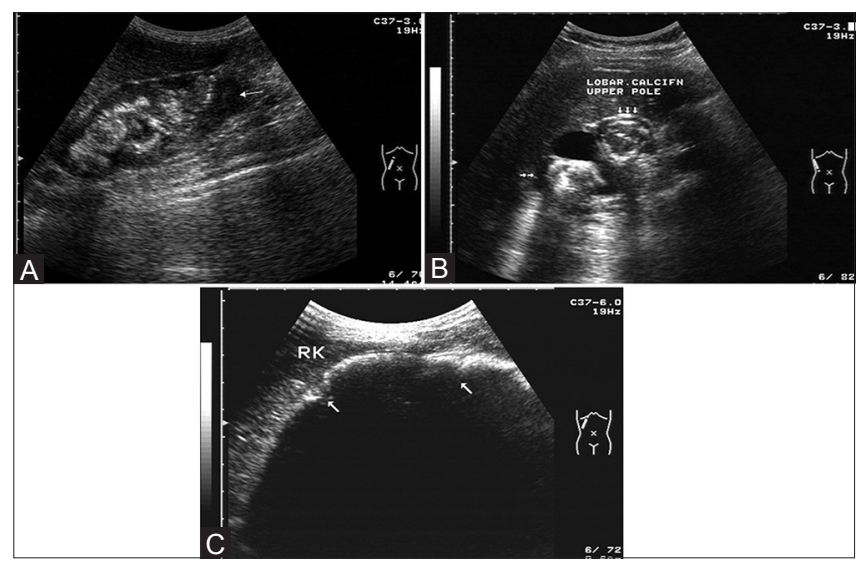

Figure 28: (A) Ultrasonography (USG) image revealing caseation with a developing lobar pattern of calcification, in almost all calyces, barring the lower group of calyces (white arrow) (B) Ultrasonography (USG) image revealing classic "lobar calcification"- pathognomonic of renal tuberculous (C) Ultrasonography (USG) image revealing a densely calcified kidney producing acoustic shadowing that obscures underlying details. White arrows point to junctions between the renal lobes

will help in confirming the lack of flow within the destroyed parenchyma and also highlight granulomas [Figure 27B]. A lobar pattern of caseation, akin to the lobar pattern of calcification, can be virtually diagnostic on cross-sectional imaging.

Focal calcification may be seen as highly echogenic areas with distal shadowing and, in most cases, will represent a healed granulomatous process. Parenchymal calcification may be accompanied by overlying cortical scars.

Calcification may be punctate or dense, within a visible renal mass, or in the infected parenchyma. In the PCS,

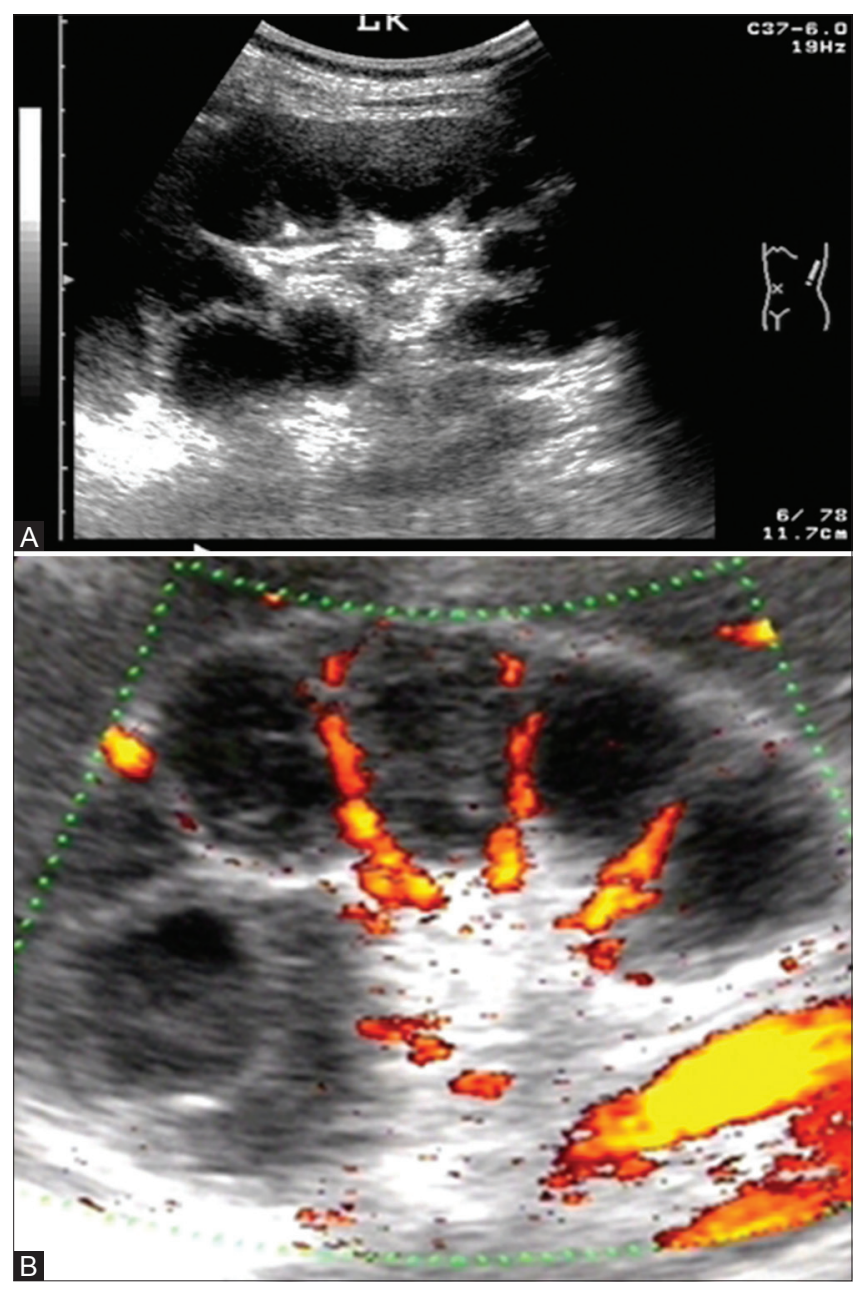

Figure 27: (A) Ultrasonography (USG) image revealing lobar caseation (A) Grey scale and, (B) Color flow image demonstrating presence of renal vasculature only between the caseated lobes

speckled or curvilinear calcifications may also be noted in the walls of the calyces, pelvis, or ureter. Faint/early ureteral calcification, a very good pointer toward UTB, may be missed on USG. A careful look at the plain film will help avoid this pitfall. USG is also unable to distinguish between the various types of calcifications that occur. ${ }^{[76]}$ However, if looked carefully, the characteristic 'lobar pattern' of calcification is easily demonstrable on USG [Figure 28A-C]. Involvement of even a single lobe can be diagnostic of renal TB. Small calculi may not be identifiable at times, as they do not shadow in the midst of surrounding fibrotic tissue. ${ }^{[4]}$ USG elastography/tissue strain analytics [including exciting new variants such as acoustic radiation force impulse (ARFI) technology, for evaluation of deep tissues not accessible by superficial compression elastography] have the potential to evaluate fibrosis, and thus to contribute further to treatment planning.

In addition to dense areas of calcification, approximately $25 \%$ of patients with renal TB demonstrate tumefactive masses similar to those seen in XPN [Figure 19]. Air within 
the collecting system may indicate the presence of an enteric fistula. Residual functional tissue left in a densely calcified kidney is poorly seen on USG and is best evaluated by $\mathrm{CT}^{[76]}$ with nuclear scintigraphy and MRI being the other options.

CT urography (CTU) performed on the current high-end MDCT scanners have the potential to detect early TB changes that were usually noted on IVU. Hence, familiarity with the IVU changes of renal TB remains necessary. These, along with other $\mathrm{CT}$ and MRI findings in renal TB, will be covered in part II of this review article.

\section{References}

1. Muttarak M, Chiang Mai WN, Lojanapiwat B. Tuberculosis of the genitourinary tract: Imaging features with pathological correlation. Singapore Med J 2005;46:568-74.

2. Global tuberculosis control: Key findings from the December 2009 WHO report. Wkly Epidemiol Rec 2010;85:69-80.

3. Chauhan LS, Tonsing J. Revised national TB control programme in India. Tuberculosis (Edinb) 2005;85:271-6.

4. Burrill J, Williams CJ, Bain G, Conder G, Hine AL, Misra RR. Tuberculosis: A radiologic review. Radiographics 2007;27:1255-73.

5. Craig WD, Wagner BJ, Travis MD. Pyelonephritis: Radiologic-pathologic review. Radiographics 2008;28:255-77.

6. Merchant SA.Tuberculosis of the genitourinary system. IndianJ RadiolImaging 1993;3:253-74.

7. Wilberschied LA, Kaye K, Fujiwara PI, FriedenTR. Extrapulmonary tuberculosis among foreign-born patients, New York City, 1995 to 1996. J Immigr Health 1999;1:65-75.

8. Wise GJ. Urinary tuberculosis: Modern issues. CurrUrol Rep 2009;10:313-8.

9. Engin $G$, Acunaş B, Acunaş G, Tunaci M. Imaging of extrapulmonary tuberculosis. Radiographics 2000;20:471-88.

10. Goel A, Seth A, Kumar R. Autocystectomy following extensive genitourinary tuberculosis: Presentation and management. IntUrolNephrol 2002;34:325-7.

11. Kennedy DH: Extrapulmonary tuberculosis. In: The Biology of the Mycobacteria, Vol. III, edited by Ratledge C, Stanford JL, Grange JM, New York, Academic Press, 1989, pp 245-284.

12. Gupta NP. Genitourinary tuberculosis. Indian J Urol 2008;24:355.

13. NaidichDP, GaraySM, LeitmanBS, McCauley DI. Radiographic manifestations of pulmonary disease in the acquired immunodeficiency syndrome (AIDS). SeminRoentgenol 1987;22:14-30.

14. JohnsonCW, Lowe FC, Warren JW, HebelJR. Genitourinary tuberculosis. AUA Update Ser 2003;22:303-7.

15. Nzerue C, Drayton J, Oster R, Hewan-Lowe K. Genitourinary tuberculosis in patients with HIV infection: Clinical features in an inner-city hospital population. Am J Med Sci 2000;320:299-303.

16. Wise GJ, Shteynshlyuger A. An update on lower urinary tract tuberculosis. CurrUrol Rep 2008;9:305-13.

17. Tonkin AK, Witten DM. Genitourinary tuberculosis. SeminRoentgenol 1979;14:305-18.

18. Caskurlu T, Resim S, Bayraktar Z, Taşçi AI, Sevin G. Urinary tuberculosis in a two-year-old boy. Int Urol Nephrol 1998;30:525-8.

19. Bugbee H. Tuberculoma of the kidney: Reportofacase. J Urol 1941;46:355-85.

20. Wang LJ, Wong YC, Chen CJ, Lim KE. CT features of genitourinary tuberculosis. J Comput Assist Tomogr 1997;21:254-8.
21. Gibson MS, Puckett ML, Shelly ME. Renal tuberculosis. Radiographics 2004;24:251-6.

22. Christensen WI. Genitourinary tuberculosis: Review of 102 cases. Medicine (Baltimore) 1974;53:377-90.

23. Narayana A. Overview of renal tuberculosis. Urology 1982;19:231-7.

24. Simon HB, Weinstein AJ, Pasternak MS, Swartz MN, Kunz LJ. Genitourinary tuberculosis. Clinical features in a general hospital population. Am J Med 1977;63:410-20.

25. Kenney PJ. Imaging of chronic renal infections. AJR Am J Roentgenol 1990;155:485-94.

26. Pastsernak MS, RubinRH. Urinary tract tuberculosis.In: Schrier RW, editor. Diseases of the Kidney and Urinary Tract. $7^{\text {th }}$ ed. Philadelphia, PA: Lipincott Williams and Wilkins; 2001. p. 1017-37.

27. Wang LJ, Wong YC, Chen CJ, Lim KE. CT features of genitourinary tuberculosis. J Comput Assist Tomogr 1997;21:254-8.

28. Togao O, Doi S, Kuro-o M, Masaki T, Yorioka N, Takahashi M. Assessment of renal fibrosis with diffusion-weighted MR imaging: Study with murine model of unilateral ureteral obstruction. Radiology 2010;255:772-80.

29. Noguchi T, Yoshiura T, Hiwatashi A, Togao O, Yamashita K, Nagao E, et al. CT and MRI findings of human herpesvirus 6-associated encephalopathy: Comparison with findings of herpes simplex virus encephalitis. AJR Am J Roentgenol 2010;194:754-60.

30. Tobin-D'Angelo MJ, Blass MA, del Rio C, Halvosa JS, Blumberg HM, Horsburgh CR Jr. Hospital water as a source of Mycobacterium avium complex isolates in respiratory specimens. J Infect Dis 2004;189:98-104.

31. Qunibi WY, al-Sibai MB, Taher S, Harder EJ, de Vol E, al-Furayh $\mathrm{O}$, et al. Mycobacterial infection after renal transplantation-Report of 14 cases and review of the literature. Q J Med 1990;77:1039-60.

32. Das KM, Indudhara R, Vaidyanathan S. Sonographic features of genitourinary tuberculosis. AJR Am J Roentgenol 1992;158:327-9.

33. Lamm DL. Complications of bacillus Calmette-Guérin immunotherapy. UrolClin North Am 1992;19:565-72.

34. Garcia JE, Thiel DD, Broderick GA. BCG pyelonephritis following intravesical therapy for transitional cell carcinoma. Can J Urol 2007; 14:3523-5

35. Hartman DS, Stagg PL. Diagnosis please. Case 3: Renal tuberculosis. Radiology 1998;209:69-72.

36. Birnbaum BA, Friedman JP, Lubat E, MegibowAJ, BosniakMA. Extrarenal genitourinary tuberculosis: $\mathrm{CT}$ appearance of calcified pipe-stem ureter and seminal vesicle abscess. J Comput Assist Tomogr 1990;14:653-5.

37. Rook GA. The role of vitamin D in tuberculosis. Am Rev Respir Dis 1988;138:768-70.

38. Davies PD. The role of vitamin D in tuberculosis. Am Rev Respir Dis 1989;139:1571.

39. Elkin M. Urogenital tuberculosis. In: PollackHM, editor. Clinical Urography. Philadelphia: WB Saunders; 1990.p. 1020-52.

40. Eastwood JB, Corbishley CM, Grange JM. Tuberculosis and the kidney. J Am SocNephrol 2001;12:1307-14.

41. Elkin M. Radiology of the urinary system. Boston: Little Brown and Company; 1980. p. 148-152.

42. Vijayaraghavan SB, Kandasamy SV, Arul M, Prabhakar M, Dhinakaran CL, Palanisamy R. Spectrum of high-resolution sonographic features of urinary tuberculosis. J Ultrasound Med 2004;23:585-94.

43. Pouchot J, Dreyfuss D, Gardin JP, Mier L, Rémy P, Esdaile JM, et al. Ectopic production of 1,25-dihydroxyvitamin D3 in tuberculosis. Nephrol Dial Transplant 1993;8:560-2. 
44. Gurski J, Baker KC. An unusual presentation: Renal tuberculosis. Scientific World Journal 2008;8:1254-5.

45. Goldman SM, Fishman EK. Upper urinary tract infection: The current role of CT, ultrasound, and MRI. Semin Ultrasound CTMR 1991;12:335-60.

46. Gow JG. Renal calcification in genito-urinary tuberculosis. Br J Surg 1965;52:283-8.

47. El-Reshaid KA, Madda JP, Al-Saleh MA. A case of progressive tubulo-interstitial nephritis due to culture-negative renal tuberculosis. Saudi J Kidney Dis Transpl 2001;12:534-7.

48. Sampathkumar K, Sooraj YS, Mahaldar AR, Ramakrishnan M, Rajappannair A, Nalumakkal SV, et al. Granulomatous interstitial nephritis due to tuberculosis: A rare presentation. Saudi J Kidney Dis Transpl 2009;20:842-5.

49. Mignon F, Méry JP, Mougenot B, Ronco P, Roland J, Morel-Maroger L, et al. Granulomatous interstitial nephritis. Adv Nephrol Necker Hosp 1984;13:219-45.

50. Bijol V, Mendez GP, Nosé V, Rennke HG. Granulomatous interstitial nephritis: A clinicopathologic study of 46 cases from a single institution. Int J SurgPathol 2006;14:57-63.

51. Modesto A, Marty L, SucJM, Kleinknecht D, de Frémont JF, Marsepoil T, et al. Renal complications of intravesical bacillus Calmette-Guérin therapy. Am J Nephrol 1991;11:501-4.

52. Krishnamoorthy S, Gopalakrishnan G. Surgical management of renal tuberculosis. Indian J Urol 2008;24:369-75.

53. RoseBD, Renal disease in tuberculosis, 2007. Available from: www. uptodate.com

54. Daher Ede F, Silva Júnior GB, Damasceno RT, Santos GM, CorsinoGA, Silva SL, et al. End-stage renal disease due to delayed diagnosis of renal tuberculosis: A fatal case report. Braz J Infect Dis 2007;11:169-71.

55. Wise GJ, Marella VK. Genitourinary manifestations of tuberculosis. Urol Clin North Am 2003;30:111-21.

56. Shribman JH, Eastwood JB, Uff J. Immune complex nephritis complicating miliary tuberculosis. Br Med J (Clin Res Ed) 1983;287:1593-4.

57. Conde Redondo C, Estébanez Zarranz J, Rodríguez Toves A, de Castro Olmedo C, Camacho Parejo J, Sanz Santacruz J, et al. Tuberculosis and renal cancer. ActasUrolEsp 1999;23:617-20.

58. Peyromaure M, Sèbe P, Darwiche F, Claude V, Ravery V, Boccon-Gibod L. Renal tuberculosis and renal adenocarcinoma: A misleading association. ProgUrol 2002;12:89-91.

59. Feeney D, Quesada ET, Sirbasku DM, Kadmon D. Transitional cell carcinoma in a tuberculous kidney: Case report and review of the literature. J Urol 1994;151:989-91.

60. Kamat AV, Goldsmith D, O'Donnell P, van der Walt J, Carr R. Renal failure with granulomatous interstitial nephritis and diffuse leukemic renal infiltration in chronic lymphocytic leukemia. Ren Fail 2007;29:763-5.

61. Simões do Espírito Santo K, Teixeira Vde P, Costa Hde O, Franco M. Renal tuberculosis in adult polycystic kidney disease: Report of 2 cases and review of the literature. Int J SurgPathol 2007;15:196-8.

62. Casas JD, Cuadras P, Mariscal A, Domènech S. Replacement lipomatosis related to renal tuberculosis: Imaging findings in one case. EurRadiol 2002;12:810-3.

63. Jafri SZ, Roberts JL, Berger BD. Fistulas of the genito urinary tract. In: Pollack HM, editor. Clinical Urography. $2^{\text {nd }} e d$. Philadelphia: Saunders; 2000.p. 2992-3011

64. Shah HN, Jain P, Chibber PJ. Renal tuberculosis simulating xanthogranulomatous pyelonephritis with contagious hepatic involvement. Int J Urol 2006;13:67-8.

65. Chugh KS, Datta BN, Singhal PC, Jain SK, Sakhuja V, Dash SC. Pattern of renal amyloidosis in Indian patients. Postgrad Med J $1981 ; 57: 31-5$
66. Byrd RB, Viner NA, Omell GH, Trunk G. Leukoplakia associated with renal tuberculosis in the chemotherapeutic era. Br J Urol 1976;48:377-81.

67. Figueiredo AA, Lucon AM. Urogenital tuberculosis: Update and review of 8961 cases from the world literature. Rev Urol 2008;10:207-17.

68. Mesquita M, Libertalis M, Bakoto ES, Vandenhoute K, Damry N, Guillaume MP. Late diagnosis of extra-pulmonary tuberculosis leads to irreversible kidney failure in a non-immunocompromised patient. Int Urol Nephrol 2010;42:227-32.

69. Becker JA. Renal tuberculosis. UrolRadiol 1988;10:25-30.

70. Kollins SA, Hartman GW, Carr DT, Segura JW, Hattery RR. Roentgenographic findings in urinary tract tuberculosis. A 10 year review. Am J Roentgenol Radium Ther Nucl Med 1974;121:487-99.

71. Hartman DS. Radiologic, pathologic correlation of the granulomatous lesions of the kidney. In: Stamey TA, editor. MonographsinUrology. Burroughs Wellcome Company, London1985.

72. Amis SE, Newhouse JH. Essentials of Uroradiology. Boston: Litt le Brown and Company; 1991. p. 164-6.

73. Tuberculosis of the kidney.In: Ney C, Friedenberg RM (eds)., editors. Radiographic Atlas of the Genitourinary System. Philadelphia: JB Lippincott Company; 1981.

74. Harisinghani MG, Mc Loud TC, Shepard JA, Ko JP, Shroff MM, Mueller PR. Tuberculosis from head to toe. Radiographics 2000;20:449-70.

75. Davidson AJ, Hartman DS, Choyke PL, Wagner BJ. Davidson's radiology of the kidney and genito-urinary tract $3^{\text {rd }}$ ed. Philadelphia, Pa: Saunders, 1999;41-72.

76. Premkumar A, Lattimer J, Newhouse JH. CT and sonography of advanced urinary tract tuberculosis. AJR Am J Roentgenol 1987;148:65-9.

77. Apperson JW, Wechsler H, Lattimer JK. The trequent occurrence of both renal calculi and renal calcifications in tuberculous kidneys. J Urol 1962;87:643-6.

78. Kapoor R, Ansari MS, Mandhani A, Gulia A. Clinical presentation and diagnostic approach in cases of genitourinary tuberculosis. Indian J Urol 2008;24:401-5.

79. Navarro-Vilasaró M, Font B, Sala M, Prera A, Malet A, Mariscal D, et al. Genitourinary mycobacteriosis: Retrospective study of 45 cases in a general hospital. EnfermInfeccMicrobiolClin 2008;26:540-5.

80. Brasch WF. Roentgenographic diagnosis in renal tuberculosis. Surg Gynecol Obst 1919;28:555-61.

81. Taylor H. Renal tuberculosis pathogenesis and Roentgen findings. AJR Am J Roentgenol1939;42:700-8.

82. Benjamin JA, Taylor HB. Renal tuberculosis and tuberculous perinephric abscess. JUrol 1945;53:265-8.

83. Rose AG. Diseases of medium-sized arteries, including hypertension. In: Silver MD, editor. Cardiovascular Pathology, $1^{\text {st }}$ ed. New York, Edinburg, London, Melbourne: Churchill Livingstone Inc; 1983, pp 739-776.

84. Kollins SA, Hartman GW, Carr DT, Segura JW, Hattery RR. Roentgenographic findings in urinary tract tuberculosis. A 10 year review. Am J Roentgenol Radium TherNucl Med 1974;121:487-99.

85. Hanley HG. Conservative surgery in renal tuberculosis, including renal cavernotomy. Br J Surg 1961;48:415-20.

86. Sanematsu H, Nakao T, Yoshiura T, Nabeyama M, Togao O, Tomita $\mathrm{M}$, et al. Predictors of treatment response to fluvoxamine in obsessive-compulsive disorder: An fMRI study. J Psychiatr Res 2010;44:193-200.

87. Navarová J, Ujházy E, Dubovický M, Mach M. Effect of melatonin on biochemical variables induced by phenytoin in organs of 
mothers, foetuses and offsprings of rats. Cent Eur J Public Health 2004;12:S67-9.

88. Frimann-Dahl J. Radiological investigations of urogenital tuberculosis. UrolInt 1955;1:396-426.

89. Colabawalla B.Reflections on urogenital tuberculosis. Indian J Urol 1990;6:51-9.

90. Barrie HJ, Kerr WK, Gale GL. The incidence and pathogenesis of tuberculous strictures of the renal pyelus. J Urol 1967;98:584-9.

91. Brennan RE, Pollack HM. Nonvisualized ("phantom") renal calyx: Causes and radiological approach to diagnosis. UrolRadiol 1979;1:17-23

92. Wang LJ, Wu CF, Wong YC, Chuang CK, Chu SH, Chen CJ. Imaging findings of urinary tuberculosis on excretory urography and computerized tomography. J Urol 2003;169:524-8.

93. Yu NC, Raman SS, Patel M, Barbaric Z. Fistulas of the genitourinary tract: A radiologic review. Radiographics 2004;24:1331-52.

94. Schwartz DT, GarnesHA, Lattimer JK, Roberts TW. Pyeloduodenal fistula due to tuberculosis. J Urol 1970;104:373-5.

95. Dunn M, Kirk D. Renogastric fistula: Case report and review of the literature. J Urol 1973;109:785-7.

96. Hanchanale V, Rao A, Motiwala H. Renogluteal fistula: An unusual complication of genito-urinary tuberculosis. Indian J Urol 2006;22:270-1.

97. Chen KC. Lymphatic abnormalities in patients with chyluria. J Urol 1971;106:111-4.

98. Kim SH. Urogenital tuberculosis. In: Pollack HM, McClennan BL (eds)editors. ClinicalUrography. $2^{\text {nd }}$ ed. Philadelphia, PA: WB Saunders Co.; 2000. p. 1193-1228

99. Weil FS, Bihr E, Rohmer P, Zeltner F. Renal Sonography. $2^{\text {nd }}$ ed. New York: Springer-Verlag; 1987. p. 210

100. Schaffer R, Becker JA, Goodman J. Sonography of tuberculous kidney. Urology 1983;22:209-11.

101. Juul N, Torp-Pedersen S, Grønvall S, Holm HH, Koch F, Larsen S. Ultrasonically guided fine needle aspiration biopsy of renal masses. J Urol 1985;133:579-81.

102. Das KM, Vaidyanathan S, Rajwanshi A, Indudhara R. Renal tuberculosis: Diagnosis with sonographically guided aspiration cytology. AJR Am J Roentgenol 1992;158:571-3.

103. Rui X, Li XD, Cai S, Chen G, Cai B. Ultrasonographic diagnosis and typing of renal tuberculosis. Int J Urol 2008;15:135-9.

104. Browne RF, Zwirewich C, Torreggiani WC. Imaging of urinary tract infection in the adult. EurRadiol 2004;14:E168-83.

105. Papanicolaou N, Pfister RC. Acute renal infections. Radiol Clin North Am 1996;34:965-95.

106. Cook JH $3^{\text {rd }}$, Rosenfield AT, Taylor KJ. Ultrasonic demonstration of intrarenal anatomy. AJR Am J Roentgenol 1977;129:831-5.

107. Lee JK, McClennan BL, Melson GL, Stanley RJ. Acute focal bacterial nephritis: Emphasis on gray scale sonography and computed tomography. AJR Am J Roentgenol 1980;135:87-92.

108. Moussa OM, Eraky I, El-Far MA, Osman HG, Ghoneim MA Rapid diagnosis of genitourinary tuberculosis by polymerase chain reaction and non-radioactive DNA hybridization. J Urol 2000;164:584-8.

109. Vourganti S, AgarwalPK, BodnerDR, DograVS. Ultrasonographic evaluation of renal infections. RadiolClin North Am 2006;44: 763-75.

110. Khanna PC, Merchant S, Joshi AR.Omental cake from tuberculosis. Appl Radiol Imaging 2007;36:5.

Cite this article as: Merchant S, Bharati A, Merchant N. Tuberculosis of the genitourinary system-Urinary tract tuberculosis: Renal tuberculosis-Part I. Indian J Radiol Imaging 2013;23:46-63.

Source of Support: Nil, Conflict of Interest: None declared.

\section{Staying in touch with the journal}

1) Table of Contents (TOC) email alert

Receive an email alert containing the TOC when a new complete issue of the journal is made available online. To register for TOC alerts go to www.ijri.org/signup.asp.

\section{2) RSS feeds}

Really Simple Syndication (RSS) helps you to get alerts on new publication right on your desktop without going to the journal's website. You need a software (e.g. RSSReader, Feed Demon, FeedReader, My Yahoo!, NewsGator and NewzCrawler) to get advantage of this tool. RSS feeds can also be read through FireFox or Microsoft Outlook 2007. Once any of these small (and mostly free) software is installed, add www.ijri.org/rssfeed.asp as one of the feeds. 